
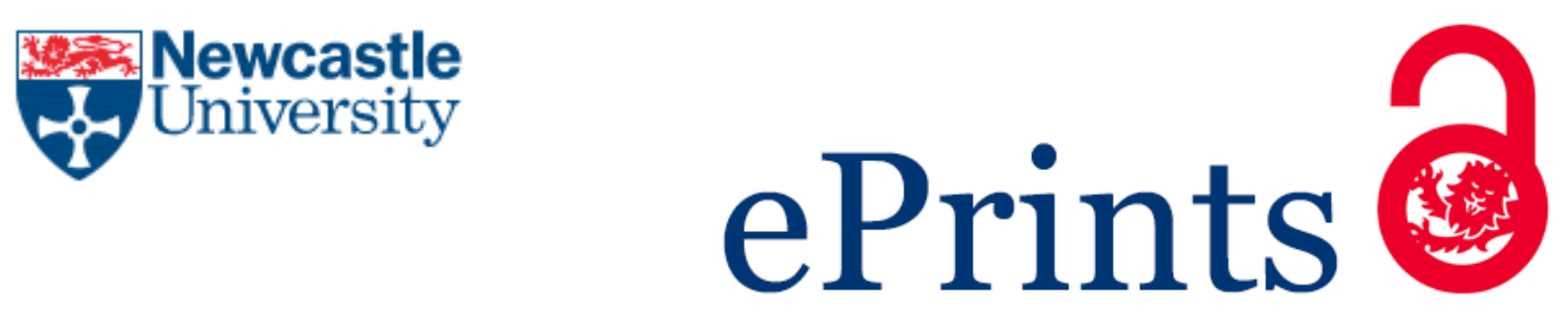

Nasirahmadi A, Edwards SA, Sturm B.

Implementation of machine vision for detecting behaviour of cattle and pigs.

Livestock Science 2017, 202, 25-38.

\title{
Copyright:
}

(C) 2017. This manuscript version is made available under the CC-BY-NC-ND 4.0 license

DOI link to review:

https://doi.org/10.1016/j.livsci.2017.05.014

Date deposited:

$11 / 07 / 2017$

Embargo release date:

19 May 2018

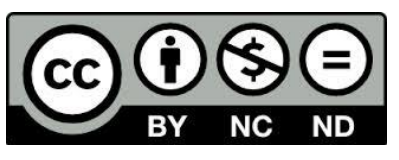

This work is licensed under a

Creative Commons Attribution-NonCommercial-NoDerivatives 4.0 International licence 


\section{Implementation of machine vision for detecting behaviour of cattle and pigs}

$7 \quad$ Abstract
Abozar Nasirahmadi ${ }^{1,2}$, Sandra A. Edwards ${ }^{1}$, Barbara Sturm ${ }^{1,2}$

${ }^{1}$ School of Agriculture, Food and Rural Development, Newcastle University, Newcastle upon Tyne NE1 7RU, UK

${ }^{2}$ Department of Agricultural and Biosystems Engineering, University of Kassel, 37213 Witzenhausen, Germany

Livestock production to provide food for a growing world population, with increasing demand for meat and milk products, has led to a rapid growth in the scale of cattle and pig enterprises globally. However, consumers and the wider society are also increasingly concerned about the welfare, health and living conditions of farm animals. Awareness of animal needs underpins new production standards for animal health and welfare. Pig and cattle behaviour can provide information about their barn environmental situation, food and water adequacy, health, welfare and production efficiency. Real-time scoring of cattle and pig behaviours is challenging, but the increasing availability and sophistication of technology makes automated monitoring of animal behaviour practicable. Machine vision techniques, as novel technologies, can provide an automated, non-contact, non-stress and cost-effective way to achieve animal behaviour monitoring requirements. This review describes the state of the art in 3D imaging systems (i.e. depth sensor and time of flight cameras) along with 2D cameras for effectively identifying livestock behaviours, and presents automated approaches for monitoring and investigation of cattle and pig feeding, drinking, lying, locomotion, aggressive and reproductive behaviours. The performance of developed systems is reviewed in terms of sensitivity, specificity,

\footnotetext{
${ }^{1}$ Corresponding author: abozar.nasirahmadi@ncl.ac.uk, a.nasirahmadi@gmail.com
} 
accuracy, error rate and precision. These technologies can support the farmer by monitoring normal behaviours and early detection of abnormal behaviours in large scale enterprises.

Keywords: Behaviour, cattle, machine vision, pig, precision livestock farming

\section{Introduction}

Livestock production is the largest user of land in the world for grazing and production of feed grains. The global demand for livestock products is expected to further increase due to population growth, rising incomes and urbanisation (Bruinsma, 2003). Increase in market demand for meat and milk products, to provide food for a growing population, has led to a rapid growth in the scale of cattle and pig enterprises globally. As the scale of animal husbandry around the world increases, addressing the issue of animal welfare becomes more essential. The relationship that people have with animals, and the duty they have to ensure that the animals under their care are treated correctly, is fundamental to animal welfare. Due to the current scale of production, there is increasing awareness that the monitoring of animals can no longer be done by farmers in the traditional way and requires the adoption of new digital technologies.

Livestock welfare can be defined using such parameters as their behaviour, physiology, clinical state and performance (Averós et al., 2010; Costa et al., 2014; Nasirahmadi et al., 2015). There are many links between animal behaviour, health, emotions and good welfare which have been widely reviewed (e.g. Broom, 2006; Bracke and Spoolder, 2011; Murphy et al., 2014), and identification of normal and abnormal behaviours helps to deliver better health, welfare and production efficiency (Nasirahmadi et al., 2017). Early and real-time detection of normal behaviours (e.g. lying, feeding and drinking) and abnormal behaviours (e.g. aggression and 
mortality, and improves the job satisfaction of stockpeople. The advancement of knowledge and technology in the current century, along with human expectations for a sufficiency of highquality livestock products, has increased demand for improved production monitoring. With the development of new technologies, the application and integration of new sensors and interpretation of data from multiple systems with reducing processing times means that information supply for farmers and researchers has become easier (Barkema et al., 2015).

There are many studies in the literature that demonstrate how such technologies can help in observation of both normal and abnormal behaviours of animals. Examples include using radio frequency systems for locating animals, which utilize sensors and radio signals from a transmitter to triangulate a location, and the use of these location data to provide information on feeding and drinking behaviours of cattle (Sowell et al., 1998; Quimby et al., 2001; Wolfger et al., 2015; Shane et al., 2016) and pigs (Reiners et al., 2009; Brown-Brandl et al., 2013; Andersen et al., 2014; Maselyne et al., 2014; Gertheiss et al., 2015). Further examples of the application of new technology are activity and lying behaviour monitoring in cattle and pigs using accelerometers attached to the animals (Robert et al., 2009; Trénel et al., 2009; Ringgenberg et al., 2010; Jónsson et al., 2011). This technique has been widely applied for locomotion and lameness assessment (e.g. Nielsen et al., 2010; Grégoire et al., 2013; Conte et al., 2014), as has the use of other sensors which have been reviewed by (Rutten et al., 2013; Schlageter-Tello et al., 2014; Van Nuffel et al., 2015) for cows and (Nalon et al., 2013) for pigs. However, attachment of sensors to monitor animal behaviours may cause stress and, in some cases, is impractical to use for scoring group behaviours due to their cost and vulnerability. An alternative technology which has been widely considered in many agricultural and industrial processes is machine vision (Shao and Xin, 2008; Costa et al., 2014; Nasirahmadi et al., 2016b; Oczak et al., 2016). Automatic computer imaging systems could help both farmers and researchers to address the problems of monitoring animals, e.g. for visual 
scoring, animal weighing and other routine tasks which are both time-consuming and costly, and could result in more objective measurements by means of image processing techniques. A machine vision approach is a cheap, easy, non-stressful and non-invasive method which can be adapted to different animals, in both indoor and outdoor situations, using the animals' natural features (e.g. shape, colour, movement) for monitoring their behaviours.

This review summarises machine vision and image processing techniques to automatically measure cattle and pig characteristics and behaviours. The article is structured in nine sections. Section 2 covers different types of camera and imaging systems used in this field. Section 3 and its subsections illustrate the use of image processing for individual physical characterization of cattle and pigs. Section 4 addresses feeding and drinking behaviours, section 5 discusses lying behaviours and section 6 covers how image processing is used for detection of lameness and normal locomotion. Section 7 illustrates automatic monitoring of aggressive behaviours of animals, while section 8 shows how mounting behaviours of cattle and pigs can be captured by image processing. Challenges and future research needs for animal monitoring are discussed in section 9. Finally, conclusions are presented in section 10.

\section{Imaging systems for livestock monitoring}

Image acquisition, which is the first step of any machine vision system, is defined as the transfer of signals from a sensing device (i.e. camera) into a numeric form. Cameras are a crucial element in machine vision applications, however, each type of camera offers different information on parameters of the image. For the purposes of this literature review, the cameras applied in cattle and pig behaviour detection can be divided into Charge Coupled Device (CCD), infrared and depth sensor cameras. The CCD cameras create images in two dimensions and are sensitive to visible wavelength bands reflected from objects (Mendoza et al., 2006). 
These types of camera need an additional source of light to make the image visible and the machine vision system consists of single or multiple cameras, e.g. video surveillance cameras, capturing objects which are visible to a human. Examples of using this type of camera in livestock behaviour detection are numerous (Shao et al., 1998; Hu and Xin, 2000; Porto et al., 2015; Nasirahmadi et al., 2016b). The captured images are potentially suitable for image processing algorithms to extract image features based on colour, shape and textural properties. CCD cameras have the ability to provide pixels of objects in red, green and blue (RGB) bands. Nowadays, different image processing algorithms help to convert these bands to information on grey, hue, saturation, intensity and other parameters.

Infrared or thermal cameras work similarly to optical or common CCD cameras, in that a lens focuses energy onto an array of receptors to produce an image. By receiving and measuring infrared radiation from the surface of an object, the camera captures information on the heat that the object is emitting and then converts this to a radiant temperature reading (James et al., 2014; Matzner et al., 2015). Thus, while CCD cameras measure the radiation of visible bands, thermal cameras detect the characteristic near-infrared radiation (typically wavelengths of 8$12 \mu \mathrm{m}$ ) of objects (McCafferty et al., 2011). Thermal imaging was developed for industrial, medical and military applications, but it has also been applied in many livestock production studies, as reviewed by (Eddy et al., 2001; Gauthreaux and Livingston, 2006; McCafferty, 2007; McCafferty et al., 2011). All live animals emit infrared radiation, and the higher the temperature of an object, the greater the intensity of emitted radiation and thus the brighter the resulting image (Kastberger and Stachl 2003; Hristov et al., 2008).

In the last decade, the number of applications related to 3D imaging systems in machine vision has been growing rapidly, thanks to improved technology and reducing cost. The use of this type of imaging system in agricultural products has been recently described by (VázquezArellano et al., 2016). Depth imaging is a core component of many machine vision systems 
and, within this technology, time of flight (TOF) and Kinect cameras have been used widely in livestock applications. TOF cameras sense depth by emitting a pulse and then measuring the time differential for that emitted light to travel to an object and back to a detector. They can provide a 3D image using an infrared light source and CCD detector (Kolb et al., 2010; Pycinski et al., 2016) and the camera lens gathers the reflected light and images it onto the sensor or focal plane (Fig.1). The 3D depth sensing makes it possible to overcome common issues causing problems with 2D imaging systems, such as background removal, segmentation, feature extraction and sensitivity to lighting variance. TOF systems are limited by the number of data points that they capture at a given time and their relatively limited field of view, and the depth systems can lead to accuracy errors (Shelley, 2013). Although it is much easier and cheaper to use the 3D camera approach in farm environments rather than stereo vision, Laser or $2 \mathrm{D}$ triangulation, which are common alternatives for 3D reconstruction, the depth images still require some processing work to remove unwanted objects (e.g. noise, background) and in some cases calibration to deliver better results is needed. The Kinect depth sensor, based on the TOF principle, made it possible for software developers to acquire a skeletal model of the user in real-time (Han et al., 2013). The Kinect sensor lets the machine sense the third dimension (depth) of the object and the environment by employing data from a RGB camera, and infrared projector (Han et al., 2013; Nathan et al., 2015; Westlund et al., 2015; Marinello et al., 2015). The depth information can be useful to extract height measurements, or to calculate the real world coordinates in a much easier way as compared to $2 \mathrm{D}$ imaging systems. Furthermore, depth information can also help in extracting key features of the region of interest from the animals. For instance, Abdul Jabbar et al. (2017) utilized depth information to extract a curvedness feature to track the spine and hook bones in dairy cattle with a high detection rate 
Once the basic images have been captured from these different camera systems, image analysis techniques are carried out to interpret the information coming from the image.

\section{Image processing techniques used for characterizing individual livestock}

Although livestock usually live in groups, monitoring of individual animals is one of the main goals in many tasks. Most individual studies on cattle and pigs have been concerned with monitoring of their weight and body condition as well detection of health problems, such as mastitis in cows, through associated physical or physiological changes in the animal. Examples of such characteristics will be addressed in the following paragraphs along with the image analysis strategies applied.

\subsection{Live weight}

Knowledge of the live weight of pigs plays an important role in the control of performancerelated parameters which affect the output of the herd, i.e. animal growth, uniformity, feed conversion efficiency, space allowance, health and readiness for market (Schofield, 1990; Brandl and Jorgensen, 1996; Wang et al., 2008; Kongsro, 2014). An individual pig's live weight is usually obtained using manual or automatic weighing scales, to which pigs are driven in a way which is laborious and stressful to both the animal and the workers (Wang et al., 2008; Kongsro, 2014); furthermore, automatic scales are usually costly devices (Kongsro, 2014). Information extracted from the literature shows a range of different image processing methods for monitoring pigs' live weight. Based on length and width dimensions of pigs (i.e. length from scapula to snout, length from tail to scapula, shoulder width, breadth at middle and breadth at back) and boundary area, some researchers (Schofield, 1990; Brandl and Jorgensen, 
to obtain estimates of individual pig live weight. Live weight has also been estimated from a top view image using extracted features including area, convex area, perimeter, eccentricity, major and minor axis length and boundary detection, along with artificial neural network (ANN) methods, by Wang et al. (2008) and Wongsriworaphon et al. (2015). Recently a fully automated weight estimation technique has been introduced to estimate a marked pig's weight individually (Kashiha et al., 2014b; Shi et al., 2016). Furthermore, approaches for pig live weight estimation by means of a Kinect camera have utilized infrared depth map images (Kongsro, 2014; Zhu et al., 2015).

Similarly, image processing has been used to measure cattle live weight due to the importance of live weight monitoring for milk and meat production, along with the difficulty of manually determining live weight on farm due to stress for the animals and their potential to cause damage to themselves, humans and weighing equipment. (Tasdemir et al., 2011a; 2011b; Ozkaya, 2013) utilized top and side view cameras for cow live weight detection, using features like hip height, body length, hip width and chest depth extracted from images, along with multi linear regression and fuzzy rule models. Previously, a thermography and image analysis based method was developed by Stajnko et al. (2008) for measurement of live weight of individual bulls. The thermal camera was able to separate the bull from the surroundings accurately and the measurements were based on the tail root and front hoof templates on each image. Moreover, a TOF camera method has recently been applied for body weight detection of cows based on 3D body and contour features (Anglart, 2016).

\subsection{Body shape and condition}

Body shape and condition of a live pig/cow is an important indicator of its health, reproductive potential and value, whether for breeding or for carcass quality (Wu et al., 2004; Bercovich et al., 2013; Fischer, Luginbühl et al., 2015). Assessment of live animal body condition by eye or 
hand is time and labour intensive and highly dependent on the subjective opinion of the stockman. However, imaging methods have become more affordable, precise and fast alternatives for on-farm application. Examples of using image processing for pig body condition have used 3D cameras for shape detection (Wu et al., 2004) and thermal cameras for shape and body contour detection (Liu and Zhu, 2013). Image processing has been widely utilized for assessment of cow body condition, based on anatomical points (points around hook and tail) detected with top view CCD cameras (Bewley et al., 2008; Azzaro et al., 2011), and thermal camera measurement has been used to assess the thickness of fat and muscle layers and provide a body condition score (BCS) (Halachmi et al., 2008; Halachmi et al., 2013). In other research, the angles and distances between 5 anatomical points of the cow's back and the Euclidean distances (Ed) from each point in the normalized tail-head contour to the shape centre were used for body shape scoring (Bercovich et al., 2013). Side view images have also been used for body shape capture of cows, based on RGB images and body features (GonzálezVelasco et al., 2011; Hertem et al., 2013). In order to determine the 3D shape of a cow's body, TOF and Kinect cameras have more recently been utilized, based on extracting body features and/or back postures in 3D images (e.g. Weber et al., 2014; Salau et al., 2014; Fischer et al., 2015; Kuzuhara et al., 2015; Spoliansky et al., 2016).

\subsection{Health and disease}

Early detection of symptoms of illness or abnormal behaviour is essential to effectively deal with animal welfare and disease challenges in both cattle and pigs, and can help minimise lost production and even death of livestock. By a combination of wireless technology and image processing, a method to detect the probability of a pig being ill was tested by Zhu et al. (2009). Monitoring of a pig's daily movement, eating and drinking behaviours was considered as a tool for alarming suspected cases. The measurement of body temperature is a common method to monitor the health of an animal (Hoffmann et al., 2013). As a result, most of the research on 
health detection is based on surface temperature measurement by using thermal cameras (e.g. Schaefer et al., 2004; Montanholi et al., 2008; Rainwater-Lovett et al., 2009; Wirthgen et al., 2011; Gloster et al., 2011; Hoffmann et al., 2013). Mastitis, which is one of the most common diseases in dairy cows and causes major economic loss to dairy farmers, has been detected based on udder surface temperatures (Hovinen et al., 2008; Colak et al., 2008). Recently, a thermography method was also developed for automatic ectoparasite counting on cattle bodies to improve their health and welfare. The difference in temperatures between ectoparasites, such as ticks and horn flies, and the cow's body temperature made it possible to detect these parasites in images (Cortivo et al., 2016). However, many external parameters (e.g. high or low temperatures, soiled surfaces and variable distance from object to lens), together with difficulties in interpretation of animal surface temperature, make the real-time monitoring of health and disease using thermography more challenging. As a result, in most of the studies other methods (e.g., clinical symptoms) have been investigated for their reliability in health problem detection.

\subsection{Tracking of movement}

In order to automate monitoring of animals' health and welfare, tracking methods have been developed which differ according to animal species and husbandry situation. Livestock tracking tools based on animal-mounted identification devices can be listed as Bluetooth, WiFi networks, radio frequency methods and GPS (Huhtala, 2007). However the mentioned tools are more applicable to cattle rather than pigs. Pigs normally have more physical contact in pens and cannot easily carry measurement devices without risk of damage (Ahrendt et al., 2011). Furthermore, for large numbers of pigs many devices are needed which is not economically feasible. As a result, tracking animals by machine vision has many possible advantages in livestock monitoring. McFarlane and Schofield (1995) applied a top-down view camera for tracking piglets, based on blob edge and an ellipse fitting technique, whereas Tillett et al. (1997) 
tracked individual pigs by using $\mathrm{x}$ and $\mathrm{y}$ coordinates of shape data of individual pigs over time sequences. Furthermore, movement of pigs in a feeding stall was investigated by Frost et al. (2000) using a CCD camera. Image processing approaches have been used for tracking the location of pigs in pens by (Guo et al., 2015; Nilsson et al., 2015). In another study, different piglets were painted with different colours on their back for tracking and the automatic algorithm was based on RGB value detection (Jover et al., 2009). Similarly, (Kashiha et al., 2013b) employed a specific pattern stamped on the back of each pig and ellipse fitting algorithms to localise pigs in top view CCD images. Individual pigs were identified by their respective paint pattern using pattern recognition techniques. Recently, a real-time machine vision system for tracking of pigs was developed by Ahrendt et al. (2011), based on building up support maps and a Gaussian model of position and shape of individual pigs.

In general, to improve animal health, welfare and production efficiency, monitoring of individual animals plays an essential role in farm management. Measuring the individual weight, milk yield and lameness of dairy cows in robotic milking and using radio frequency methods to assess animal movement for health detection are some examples of technology application. Image processing techniques for individual livestock monitoring seem promising due to the drawbacks of alternative methods (e.g. price, stress of application and need for contact with the animal). The combination of imaging and sensor approaches could be more sensible in some cases. For instance the individual animal could be identified by using a sensor (i.e. radio frequency identification) while health parameters could be monitored by using image features. However, monitoring of some individual features (e.g. tracking) is still challenging, especially for animals in a herd, and the image processing methods need further development to address issues in commercial applications.

Information from the literature indicates various uses of image analysis methods in cattle and 267 pig husbandry. Other than behaviour detection, which will be addressed later in this article, 
examples include teat position detection for dairy cows, based on colour and morphology features, in robotic milking (Bull et al., 1996; Zwertvaegher et al., 2011) and milk yield estimation based on rear view depth, width and area of udder (Ozkaya, 2015). Furthermore, heat tolerance in pigs, based on surface temperature of group housed pigs, was monitored by (Brown-Brandl et al., 2013; Cook et al., 2015).

In the current section, the individual characterisation of cattle and pigs by image processing techniques has been reviewed. The detection of behaviours which may occur within the group will be addressed in the following sections. The validation scales used for evaluating a machine vision detection technique and the performance of a behaviour detection system can be described as sensitivity, specificity, error rate, precision and accuracy (table 1). All accuracy results reported here are based on correlation to ground truth. Ground truth is used in machine vision to refer to data provided by direct observation (manual scoring) in comparison to the information provided by image processing.

\section{Feeding and drinking behaviour}

Feeding and drinking behaviours contain important information that can enable better management of animals and detection of problems (Botreau et al., 2007; Chapinal et al., 2007; Brown-Brandl et al., 2013). Detecting these behaviours is therefore important from an economic and welfare point of view in animal husbandry and plays an essential role in meat and milk production. The amount of feed intake and water usage of dairy cattle affects milking efficiency (Azizi et al., 2009; Appuhamy et al., 2016) and changes in feeding and drinking behaviours in pigs can reflect pig health (Maselyne et al., 2015). Traditionally, feeding behaviour has been monitored through direct human observation or using time-lapse video recording techniques (Bach et al., 2004; Meiszberg et al., 2009), but computer controlled feeding stations are now used to register the feeding or drinking behaviours of individual 
animals using electronic tagging methods, i.e. radio frequency (Rushen et al., 2012). However,

293

294

295 such equipment is expensive and requires animals to share limited instrumented feeding locations. Recently, machine vision has been used as an alternative method for feeding and drinking behaviour detection in cattle and pigs. In order to register the presence of dairy cows in a feeding area and detect feeding behaviour, a multi-camera video system for obtaining topdown view images has been applied by (Porto et al., 2012; Porto et al., 2015), and a classifier based on the Viola-Jones algorithm (Viola and Jones, 2004) by using shapes composed of adjacent rectangles (Haar-like features, which is a digital image feature for object recognition based on the difference of the sum of pixels of areas inside the rectangles) has been developed. An image which contained the object (here cow) was considered as a positive image, whereas a negative one contained only the background of the image and did not contain the target object (cow). The ability of the system to detect cow feeding behaviour was reported to have a sensitivity of $87 \%$ when compared to visual recognition.

In another study, a feed intake monitoring system that quantified how much feed was distributed to and consumed by an individual cow was developed by Shelley (2013). A 3D imaging system was implemented to record and monitor the change in feed bins before and after feeding. The monitoring equipment measured feed intake by the change in volume assessed by recording the 3D image before and after a cow had consumed its individual daily feed. The imaging system was placed inside an enclosed box to give consistent lighting. By using shape and contour data of feed in the bin, the volumetric amount of feed was determined. Once the correlation between feed volume and image data was obtained, the process moved forward to determine an output value (weight) for the bin of feed, using a linear mapping of volume to weight by means of linear regression to derive a single weight based value of feed.

In order to automatically recognise feeding and drinking behaviours of lactating sows, a depth imaging system (Kinect) was developed by Lao et al. (2016). In this method, after removing 
unwanted objects like feeder and frame pipes, small holes from the subtraction in depth images were filled and, by converting the depth image to a binary image, the sow's physical features including the $x-y$ centroid coordinates, head and hip pixels (leftmost and rightmost pixels, respectively) were identified. Then, these features in the depth image of the sow were utilized for dividing the body into 7 parts, namely; all, upper half, lower half, head, shoulder, loin and hip. Drinking behaviour was determined by searching sow pixels connected to or near to the nipple drinker in horizontal distribution and with height greater than the height of nipple. For feeding behaviour they used the same strategy, registering when the head was in the feeder with up and down movement. An accuracy of $97.4 \%$ in feeding and $92.7 \%$ in drinking behaviours was reported for the proposed method when compared to manual scoring. Previously, a similar approach was recommended by Kashiha et al. (2013a) for automatic detection of pig water usage by means of a CCD top-view camera. The centroid of the pig's body binary image was obtained by analysis of the body contour profile, and the distances calculated between centroid of body and head, tail and ears. Drinking was defined when a pig was in the drinking area and based on distances of less than 10 pixels between head, ears and drinking nipple which lasted for at least $2 \mathrm{~s}$. Comparison of results from the developed method and the real amount of water usage indicated that the drinking behaviour was detected with an accuracy of $92 \%$.

In summary, to monitor feeding and drinking behaviours with image processing approaches, both 2D and 3D cameras have been utilized. Although, 2D monitoring is mainly based on shape and colour features of the animal, some classification models have been applied to enhance the process. However, the distance from object to camera is the main principle for $3 \mathrm{D}$ motion detection of animals. Identification of multiple animals during feeding and drinking times presents an additional challenge which is not completely solved yet by the researchers in this 
field. Furthermore, no study was found based on automatic machine vision to label each animal for the usage of feed and water in both indoor and outdoor environments.

\section{Lying behaviour}

Lying behaviour plays a critical role in determining livestock health and welfare. In dairy cattle, the lying behaviour affects the milk production, and deprivation of adequate lying time reduces welfare (Bewley et al., 2010). The duration and frequency of lying bouts are behavioural indicators of cow comfort, and adequate opportunity to rest and lie down are considered important for maximizing meat and milk production (Porto et al., 2013; Haley et al., 2000). In order to detect cows' lying behaviour in real time, a top-down view CCD camera system was developed (Cangar et al., 2008). The centre point and the orientation of cow were calculated in the first image and given to a lying detection algorithm. Lying and standing behaviours of a cow were classified as a function of time, based on the $\mathrm{x}-\mathrm{y}$ coordinates of the geometric centre of the animal, back area of cow $\left(\mathrm{m}^{2}\right)$ and the cumulative distance walked. On average $85 \%$ of lying and standing behaviours were correctly classified. Porto et al. (2013) detected cow lying behaviour with a high sensitivity (92\%) using CCD cameras and image processing based on the Viola and Jones algorithm (Viola and Jones, 2004). A multi-camera video-recording system was installed to monitor a panoramic top-down view, and positive and negative images were cropped from the panoramic top-down view image of the barn. The positive and negative images were used for training a classifier based on the Viola-Jones algorithm, and then each trained classifier was tested in testing phase. Although the pixel brightness values of the image areas of the stalls were highly variable during the daylight hours, results indicated that images used for the training and execution of the lying behaviour detector did not require any image enhancement thanks to the classification method. 
Pigs spend most of their time lying and, in some cases, older pigs lie for up to $90 \%$ of their daily time (Ekkel et al., 2003). Their lying behaviours can provide information on environmental factors affecting production efficiency, health and welfare. Temperature is the main parameter affecting pigs lying behaviour; at high environmental temperatures, pigs tend to lie down in a fully recumbent position with their limbs extended and avoid physical contact with others, while at low environmental temperatures, pigs will adopt a sternal lying posture and huddle together (Hillmann et al., 2004; Spoolder et al., 2012; Nasirahmadi et al., 2015). Design of the pen, location of feeders and drinkers, air velocity and humidity are other factors which affect the lying behaviour (Spoolder et al., 2012; Costa et al., 2014). Shao et al. 1998 used CCD cameras to obtain behavioural features from binary images of pigs, namely the Fourier transform, moments, perimeter and area, which were used as the input data to an ANN to identify pig lying behaviours. The highest rate of correct classification was obtained by combination of perimeter, area and moment. Subsequently, Shao and Xin (2008) used other features, i.e. object compactness, average frequency of pixel change from background to foreground, area occupation ratio, and moment invariant, to detect and classify lying behaviours of grouped pigs. The developed machine vision system could successfully detect motion of the pigs, segment the pigs from their background, and classify the thermal comfort state of the pigs. More recently, other studies have been carried out using imaging systems on lying behaviours of grouped pigs in different environmental situations. Costa et al. (2014) used infrared sensitive CCD cameras for detection of pig behaviours, including lying, in different conditions of ventilation rate, air speed, temperature and humidity. The difference between the pixel intensity value of an image and the previous image was taken and, from this difference, the binary activity image was calculated by setting all pixels between thresholds to 1 and others to 0 . In another project, the feasibility of using image processing and Delaunay triangulation (DT) for detection of lying behaviours of grouped pigs using top view CCD cameras was tested 
390

391

392

393

394

395

396

397

398

399

400

401

402

403

404

405

406

407

408

409

410

411

412

413

414

(Nasirahmadi et al., 2015). In each binary image, $x-y$ coordinates of each object were used for ellipse fitting algorithms to localize each pig, and ellipse parameters (Fig. 2, right) such as “Major axis length”, “Minor axis length”, “'Orientation” and "Centroid” calculated for each fitted ellipse (Kashiha et al., 2014a). Finally the centre of each ellipse was used as the point of each triangle in the DT method (Fig. 2, left). The results showed that the mean value of perimeters of each triangle was different as average temperature changed in the pig barn, giving higher values at higher environmental temperatures and reflecting the greater spacing between pigs in these conditions.

Machine vision and ANN were further developed for defining and classification of lying patterns of grouped pigs by Nasirahmadi et al. (2017). The DT features (i.e. mean value of perimeter, mean value of maximum and minimum length of side of each triangle) obtained from the binary image of lying pigs were used as input (three neurons) for an ANN classifier and the output of the classifier defined into three categories based on room set temperature: namely lower than room set temperature, higher than room set temperature and around room set temperature. The experimental data sets were randomly divided into training (70\%), validating (15\%) and testing (15\%) sets. The overall accuracy of the classifier was reported as 95.6\%. The relative operation characteristic (ROC), comprising both the sensitivity (equivalent to true positive rate) and complement of specificity to unity (equivalent to false positive rate) was computed for individual thermal classes. The area under the ROC curve, which reflects the proportion of the total area of the unit square and ranges from 0.5 for models with no discrimination ability to 1 for models with best discrimination, was shown to be around 0.96 for the classifier. Furthermore, by using the major and minor axis length of each fitted ellipse, the overall lying pattern was determined as 'close pattern' when pigs (fitted ellipses) huddle together, 'far pattern' when pigs or fitted ellipses avoid touching each other and 'normal pattern' when they nearly touch each other (Fig. 3). 
415 Preventing pigs from lying in the dunging area is important, since this has negative 416 consequences for hygiene, resulting in dirtier pigs and pens (Spoolder et al., 2012). To

417 determine whether daily provision of a rooting material (maize silage) onto a solid plate in the 418 lying area of a fully slatted pen affected the lying location of grouped pigs, a machine vision 419 approach was utilised in a commercial pig farm (Nasirahmadi et al., 2016a). Pigs were monitored by top view CCD camera and each pig localized by an ellipse fitting technique, with the centre of each fitted ellipse considered as centre of each pig in the pen. Each pen was virtually subdivided into four zones; zone four being the designated lying area near to the corridor and zone one the designated dunging area against the outer wall of the barn. By finding the $x-y$ coordinates of each pig in binary images and fitting the centroid, the specific position of each pig during lying time was found in relation to the specified zones. The results indicated the ability to use the image processing technique as a quick and non-invasive method to detect pigs' lying position.

In summary, accelerometers as sensors have been used for characterizing changes in livestock postural behaviour, mainly for cattle and sows, but their limitations (i.e. risk of destruction, stress of fitting for animals and price) make them almost infeasible for grouped pig research. Consequently, CCD cameras along with classifiers have been used for monitoring of cattle and pig lying behaviour. In cattle, machine vision motion assessment has been carried out for individual cows, whereas in pigs group lying behaviours have been investigated. Image processing studies for lying behaviour qualification have been mainly based on shape features different mathematical models. 
439 Animal locomotion can correlate with changes in welfare, health status, and behavioural 440 disorders of animals (Brendle and Hoy, 2011). Manual locomotion scoring is a widely used 441 method to detect lameness in cattle. This is done by visually inspecting a cow's standing posture 442 or gait (Sprecher et al., 1997). Cows tend to exhibit gait abnormalities (or deviations from a 443 healthy gait) as a reaction to pain or discomfort. The use of sensors and different scoring methods for this lameness behaviour detection has been reviewed by (Rutten et al., 2013; Schlageter-Tello et al., 2014; Van Nuffel et al., 2015; Caja et al., 2016). In order to automate cow lameness detection, different machine vision systems have been developed. An automatic system for continuous on-farm detection and prediction of lameness developed by Song et al. (2008) used a side view CCD camera. A background subtraction method was applied to the images and the centre points of the cow's four hooves were separated and defined in different orientations (left fore, left hind, right fore, and right hind) based on the different distances between them in the image. By comparing the vertical values (y) with a pre-defined standard boundary value, and two horizontal values $(\mathrm{x})$ on each body side, the fore hoof and hind hoof were labelled. The correlation between the hoof trackway and visual locomotion scoring was obtained to check the accuracy of the method, and results showed a high average correlation coefficient (94.8\%). The presented method was not able to distinguish small changes, i.e. Score 1 and Score 2. However, it showed a relatively higher success when a simplified scoring system was applied in their study. Large variations of overlap measurements for the same individual cow were reported (1 to $12 \mathrm{~cm}$ ), even with constant gait score. Apart from the expected occlusions and camera protection problems, their results also indicated that changes in the step overlap were not consistently matched by changes in gait score. Step overlap is a variable that shows a relationship with manual gait scores, but it is not strong enough to be used as a single classifier for lameness in all cows. Later, in another approach for recording posture and movement of cows, a camera and pressure sensitive mat were used by Pluk et al. (2012). The 
exact timing and position of placement of the hoof on the ground was obtained from the pressure mat. Images from the camera, together with the position information, were used for image processing to automatically calculate the touch and release angles in the fetlock joint for the designated leg (Fig. 4). Their results indicated that, by detecting a decrease in the range of motion or an increase in the release angle of the front hooves, a large percentage of the cows could correctly be automatically detected for early lameness. In order to extract back arch, as a postural indication of lameness, Poursaberi et al. (2010) applied circle fitting and standard background subtraction techniques along with statistical filtering to get a smoothed binary edge in images. Then, the back posture analysis was done by calculating the curvature of the back of each cow during standing and walking by fitting a circle through selected points on the spine line. The average inverse radius of arc was subsequently used for lameness scoring. The sensitivity, error rate, specificity and accuracy of the method were calculated as 100, 5.26, 97.6 and $94.7 \%$ respectively. Similarly, lameness in cows detected by side view CCD camera by Viazzi et al. (2013), used back posture with an acceptable classification rate (more than 85\%). In further development of the method proposed by Poursaberi et al. (2010), the highest point in the curvature of the animal's back was found, two ellipses were fitted to the left (illustrating the shape of the back around the hip) and right (showing the shape of the back around the shoulder) sides of the highest point, and their orientations were obtained. Then, the intersection point of the two lateral axes of both ellipses, vertical distances between the highest point in the curvature and intersection point, position of the muzzle, vertical distance between the muzzle and longitudinal axis of the right ellipse were used for lameness detection. In further research by this group (Viazzi et al., 2014a), a 2D (CCD) and a Kinect depth sensor were used to measure back posture for abnormal locomotion or lameness detection. The algorithm used for the 2D camera was based on back posture recognition (Poursaberi et al., 2010; Viazzi et al., 2013), while for the 3D image processing approach, each cow was entered separately to the 
recording area. Here, to separate two consecutive cows the minimal distance along the longitudinal direction was applied, when the Kinect depth sensor calculated distance between the cow and the sensor. Then, the contour of cow back and body orientation found in the 3D image was used for lameness detection. The contour of the cow was calculated and the distance between the symmetrical axes of the binary image was used to extract the head from the body of the cow. By detecting the peak of body, the back and neck of the cow were obtained in the image. The body orientation was calculated by using the body features and then the highest pixels around the orientation axes (10\% of the cow width) represented the back spine. The highest point in the curvature of the animal's back was used for the starting point and then the same procedure as already discussed applied for the movement pattern calculation.

Recently, 3D depth video was applied in another study to detect early lameness in dairy cows (Abdul Jabbar et al., 2017). The captured top-down 3D image of the cow's body was used to segment high curvedness features of hook bones and the spine (Fig. 5). Then, by tracking the segmented regions (hook bones and spine) a proxy of locomotion was introduced in the form of height measurements from the tracked regions. This proxy was further analysed in the form of gait asymmetry to assess the locomotion and detect early lameness. An accuracy of $95.7 \%$ with a $100 \%$ sensitivity (detecting lame cows) and $75 \%$ specificity (detecting non-lame cows) was obtained using a Support Vector Machine (SVM) classifier.

Monitoring of pigs' locomotion using different technologies can serve different purposes, i.e. detection of playing and lying behaviours (Kashiha et al., 2014a), lameness detection (Van Riet et al., 2013; Nalon et al., 2013) and welfare assessment (Lind et al., 2005). In order to use image processing to assess pig locomotion, a software tool was developed based on a combination of image subtraction and automatic threshold detection methods (Lind et al., 2005). The drawback for the proposed system was that pigs had to be manually controlled by allowing them to walk one by one in front of the camera. Kongsro (2013) developed an image 
processing technique using top-down view images for pig locomotion monitoring. The RGB images were cropped automatically to focus on the significant areas of the image and then converted to grayscale. Background noise was filtered out by labelling of the biggest object after converting grey images to binary. A filter was designed to capture only pig images in cropped RGB images where the centre point was moving. The position of the head and ears of the pig were located using the width of the pig, and the positions were found using the derivative of the width curves. By finding the image map to represent total movement of the pig in a stack of added binary images, and based on the fact that the largest values would represent the pixels where the binary pig would appear most frequently, the locomotion of the pig was obtained in images. Background subtraction and ellipse fitting techniques for localizing pigs in top view images and calculating movements of ellipse features made the tracking of locomotion of pigs more accurate (89.9\%) (Kashiha et al., 2014a). The principle was based on linear movement of the centre of a fitted ellipse in different frames and the angular movement (orientation of ellipse) for tracking some marked pigs in images in a sequence of frames). Locomotion was defined as when a pig (centre of fitted ellipse) moved more than $40 \%$ of its body length (value in pixels). In order to make the technique independent to body size of the pig, the sum of linear and angular movements was divided by the length of each pig. A similar approach was used by Nasirahmadi et al. (2015) to find moving pigs during the lying periods (Fig. 6). Locomotion of groups of pigs has been obtained by finding an activity index (Ott et al., 2014). Images of each top-down CCD camera view were analysed using background subtraction algorithms, then the images were binarised to eliminate the background and noisy areas were filtered out from the image by a morphological closing operator. Calculation of the activity index was based on the difference in pixel values between the binary image at time $t$ and that at time $\mathrm{t}+1$. A significant correlation was obtained between human observation, as an 
evaluation tool, and the proposed technique. Pig group movement was also investigated by

540 (Gronskyte et al., 2015; Gronskyte et al., 2016) by means of the optical flow pattern. Optical

541 flow is defined as the distribution of the apparent velocities of objects in an image, caused by

542 the relative motion between camera and the object. The method was based on the analysis of

543 motion and the estimation included optical flow estimation, identification of pigs, optical flow

544 filtering and distortion correction, feature extraction, and frame classification. In order to 545 determine optical flow a correction method (Horn-Schunck method), available in the Matlab ${ }^{\circledR}$

546 Vision System toolbox (the Mathworks Inc., Natick, MA, USA), was applied. Thresholding of 547 the pixel colour values was applied to pig movement monitoring, then to identify individual 548 pigs colour map adjustment and filtering, blob detection, image dilation and hole filling were applied. SVM as a classifier was utilized to classify pigs' movements in different transportation and slaughterhouse situations. A $6.5 \%$ error rate was obtained from the model, however the sensitivity and specificity were high at $93.5 \%$ and $90 \%$, respectively.

Locomotion behaviour has also been investigated using the Kinect depth camera system to detect pig lameness. Movement of pigs was first captured by using the Vicon 3D optoelectronic motion analysis system to detect the characteristic locomotory changes of lame pigs (Stavrakakis et al., 2015a). This system was then compared with the Kinect sensor to distinguish sound and lame pigs by Stavrakakis et al. (2015b). Reflective markers were attached at the central nasal bone, the mid-neck proximal to shoulders (frontal to the shoulder widening), the posterior mid-thorax, anterior mid-pelvis and tail base of pigs. A high positive correlation coefficient $(P<0.001 ; r=0.994)$ between Vicon marker trajectory data and the vertical excursions of the Kinect sensor on the neck marker was found for lame pigs.

561 In conclusion, different types of automatic locomotion and lameness behaviour detection have

562 been developed. Lameness detection of cows by means of a side view CCD camera has been 
adopted in several studies, based on back posture/arch and gait asymmetry analysis. However, to have a better detection, a combination of 2D and 3D depth images has been applied in other studies. Monitoring of individual pig locomotion within groups by machine vision techniques is still challenging, due to their similarity in shape and size, so using some mark or paint on a pig's body or using radio frequency tags could be an alternative for short term locomotion tracking. Locomotion behaviour characterisation for pain assessment in lame animals, especially in pigs, still needs further effort for earlier detection in terms of applying automatic machine vision approaches for welfare improvement.

\section{Aggressive behaviour}

Aggressive behaviour in animals can be defined as behaviour which causes actual or potential harm (e.g. threat) to other animals. Most farm animals live in groups and aggressive behaviour can be observed in the first days after the mixing of unfamiliar animals, or when competition for resources occurs such as during feeding times. This behaviour can affect growth, health and welfare of animals and gives rise to economic losses from reduced performance. Most studies of aggression detect the behaviours using direct observation or video recording with subsequent human decoding. However, automatic monitoring of aggressive behaviours in livestock based on image processing methods has recently been developed. A CCD based method was applied to monitor interactions (i.e. body pushing, head butting, head pressing, body sniffing) between dairy cows (Guzhva et al., 2016). Geometric features (distances) were extracted from every pair of cows then the values were used as inputs of a SVM, with a detection accuracy of around $85 \%$.

A continuous automated detection of aggressive behaviour among pigs by means of CCD image features was developed by Viazzi et al. (2014b). Two features were extracted from the 
segmented region of the Motion History Image (MHI); i) the mean intensity of motion which

588

589

590

591

592

593

594

595

596

597

598

599

600

601

602

603

604

605

606

607

608

609

610

represents how strong and intense the motion is in the image, and ii) the occupation index which illustrates the distribution of movement inside the regions. A Linear Discriminant Analysis (LDA) was used to classify aggressive interactions in every episode with an accuracy of $89.0 \%$, sensitivity of $88.7 \%$ and specificity of $89.3 \%$. In another study, the feasibility of a method for aggressive behaviour detection based on a percentage of activity index (number of pixels of moving animals/total number of pixels) and ANN was tested (Oczak et al., 2014).

Five features (average, maximum, minimum, sum and variance) of the activity index were calculated from the recorded videos over different time intervals and classified high aggression events with a sensitivity of $96.1 \%$, specificity of $94.2 \%$ and accuracy of $99.8 \%$. The Kinect depth sensor has also most recently been utilized to recognize and classify aggressive behaviour among pigs with an accuracy of 95.7 and $90.2 \%$, respectively (Lee et al., 2016). In their study, the automatic detection and recognition of pig aggression consists of three modules; the preprocessor, the feature generator, and the aggression detector and classifier. The depth information related to pigs was obtained using a Kinect depth sensor, then five features (minimum, maximum, average, standard deviation of velocity, and distance between the pigs) were extracted from the depth image. Finally, the aggression detector classified (using SVM) the features to detect the aggressive events, based on behavioural sub-types, i.e. chasing (following another pig with biting) and head-to-head/body knocking (hitting the snout against the head/body of another pig).

In summary, although the CCD and Kinect cameras have been applied to address aggressive behaviour detection in some studies, further efforts are needed in commercial conditions to develop a reliable alarm system for farmers. 


\section{Mounting behaviour}

612 Mounting behaviour, defined as when an animal lifts its two front legs and puts these or its 613 sternum on any part of the body or head of another animal, is the most widely used indicator of reproductive behaviour for estrus detection (Rydhmer et al., 2006). In order to detect mounting among dairy cows, a top view machine vision system has been developed by Tsai and Huang (2014). In a mounting event, initially one cow closely follows another cow for a few seconds, so the following and mounting behaviours were identified based on the changes of moving object lengths in binary images in sequential frames. The following behaviour yields a moving object with the length of approximately 2-cows in images. The length of the moving object in images will then be changed to roughly 1.5 cows while they are performing the mounting behaviour. Finally, an operator (farmer) is required to view the recorded video frames to confirm that the detected results are true estrus/mounting events.

Both male and female growing pigs also perform mounting events, with different frequencies, and these can increase the risk of injuries, such as bruises, damage to the skin, lameness or leg fractures (Rydhmer et al., 2006; Nasirahmadi et al., 2016b). A system for automatic mounting event monitoring among pigs was developed by Nasirahmadi et al. (2016b) based on top view CCD cameras. After extracting frames from recorded videos, the background subtraction method was applied to detecting pigs in the pen. An ellipse fitting technique was then utilized for localization of each pig in binary images and ellipse parameters calculated for later steps. The detection rule for pig mounting events in frame sequences was based on the typical behaviour of pigs, which normally move forward and mount with their front legs onto a part of the mounted pig's body. The Euclidean distance (ED) between pigs was also used in detection of mounting event. By finding the region of interest (ROI) for each two pigs with an ED less than half of the major axis length of the fitted ellipse, the $x-y$ coordinates of the centre of the two pigs in the ROI were recorded. As the mounting event was performed, the ED between the 
head of the first pig and the tail/head or side of the second one in the ROI with a value less than a half of major/minor axis length was obtained and the two pigs considered as one in the algorithm with a major and minor axis length of 1.3 to 2 and 1.3-1.8 pig lengths, respectively (Fig. 7). Otherwise, if no mounting event occurred (e.g. two pigs just standing closely together) the model fitted an ellipse to each pig and returned a calculated ED between pigs. The proposed method yielded a sensitivity of $94.5 \%$, specificity of $88.6 \%$ and accuracy of $92.7 \%$.

The potential for automated detection of mounting behaviours has so far been little exploited in practice. Like aggressive behaviour, it relies on more complex sequence analysis involving more than one animal and is therefore more challenging than simple shape or location detection tasks which can be used for other behavioural categories. Since a mounting event involves alteration the height of animals, application of 3D depth sensors could be tested as an alternative approach to detect mounting behaviours.

\section{Challenges and future research needs}

Table 2 and 3 summarise the automatic 2D and 3D image processing methods used for the different characterisation parameters and behavioural categories in cattle and pigs which have been reviewed here. These show that both $2 \mathrm{D}$ and $3 \mathrm{D}$ machine vision systems have been most commonly applied as a cheap and non-invasive ways to detect behaviour, individual and group features in cattle and pigs. In some cases researchers have developed and tested the systems in commercial conditions, which is one of the main goals in livestock automation research.

Monitoring that can accommodate the changing features of the livestock during the whole period of husbandry (i.e. between birth and slaughter), with automatic adjustment of algorithms as animals grow or change reproductive status, is another area of research that affects the 
potential of machine vision outputs and needs to be addressed in future studies. The monitoring systems working in livestock farms can be subject to changing and challenging ambient situations (e.g. temperature, moisture, dust and light changes) and thus require a higher degree of flexibility and wider range of operation than generally taken into account by the previous studies. The combination of machine vision and multi-sensor approaches to record environmental changes may lead to improved performance of problem detection, since further sensors could compensate for some limitation of distinction of machine vision systems. For instance, simultaneous application of acoustic sensors for recording animal vocalisations could make animal welfare assessment more accurate.

Furthermore, there are major practical challenges in automation of individual livestock monitoring. Individual animal identification can be achieved using radio frequency tags which give greater reliability than image analysis due to various uncontrolled conditions in indoor and outdoor farm environments, in combination with the fact that the animals in a group (i.e. cattle and pigs) can be highly similar in shape, colour and size. Further development of different feature detection algorithms e.g. SIFT, SURF, Haar-like and machine learning approaches is essential (Olivares-Mendez et al., 2015). In the future, other imaging systems like drone-mounted cameras, which are widely used in tracking of wild animals in different outdoor situations, might be applied for tracking of extensively kept livestock. However, current systems may spook animals due to their unfamiliar noise and overhead presence, and disrupt normal behaviours. Therefore, more research is needed based on new machine learning methods and using improved technologies.

Future opportunities could lie in the development of complete real time systems to monitor animal behaviours according to their natural biology and taking account of changes in environmental parameters to allow detection of behavioural alterations. Most of the studies on 
683 livestock monitoring are based on complex programming algorithms and the system 684 operability, particularly how easy and friendly usage is for farmers, is another dimension that 685 can be improved in future. Nowadays, thanks to wide accessibility of networks and smart phone 686 devices in farms, much more research effort needs to be carried out toward availability of real687 time online monitoring with alarm systems on these devices to address the problem of commercial accessibility.

689 Livestock monitoring is accompanied by recording large amounts of video data during animal 690 husbandry; compiling and analysing these data is a challenge facing most researchers when evaluating their findings and results. Standard databases or automated data cleaning and selection could be utilized for large scale evaluation and monitoring systems to reduce costs and timing demands. However, in future, greater effort should be focused on more effective practical application of both 2D and 3D machine vision approaches to monitoring of individual and group livestock behaviours (e.g. automatic individual tracking, injurious interactions between pen mates) which are still challenging. In order to improve the efficiency, labour and energy cost of keeping large numbers of animals in commercial operations, collaboration among animal building designers, to make the farm environment more suitable for automatic monitoring, animal biologists, to define animal requirements and interpret responses, and control, process modelling and machine vision specialists, to refine available tools, is needed.

\section{Conclusions}

In conclusion, employing modern technology has helped farm managers to improve animal production and welfare and there are now many different types of machine vision techniques in the literature which could be used in new commercially-applicable technology tools. The results of this review illustrate that machine vision can be meaningfully utilized for detection 
of lying, feeding, drinking, locomotion, aggressive and reproductive behaviours of cattle and pigs. Most of the studies have focussed on the use of CCD cameras to monitor livestock behaviours, using top view images along with mathematical processing methods. Application of modern digital technologies in 3D imaging systems (Kinect, TOF cameras) offer further possibilities for improvement. With accurate information about livestock behaviours, the farmer can move quickly to address problems or seek interventions. Additionally, automated tracking of the time course and frequency of some abnormal behaviours within pens could facilitate the work of researchers exploring methods for prevention or alleviation of the behavioural problem. Although many machine vision techniques have been recently applied by researchers for livestock behaviour detection, further elaboration of image processing techniques could be an important step towards the development of an automated system that can detect behaviours of animals and decide the best solution or alarm in unusual situations.

\section{Acknowledgments}

We are grateful to two anonymous reviewers for their valuable comments and suggestions on an earlier version of this manuscript.

\section{References}

Abdul Jabbar, K., Hansen, M.F., Smith, M.L., 2017. Early and non-intrusive lameness detection in dairy cows using 3-dimensional video. Biosyst. Eng., 153, 63-69.

Ahrendt, P., Gregersen, T., Karstoft, H., 2011. Development of a real-time computer vision system for tracking loose-housed pigs. Comput. Electron. Agric. 76 (2), 169-174.

Andersen, H.M-L., Dybkjær, L., Herskin, M.S., 2014. Growing pigs' drinking behaviour: number of visits, duration, water intake and diurnal variation. Anim. 8(11), 1881-1888.

Anglart, D., 2016. Automatic estimation of body weight and body condition score in dairy cows using 3D imaging technique. Second cycle, A2E. Uppsala: SLU, Dept. of Animal Nutrition and Management. 

water intake by dairy cows. J. Dairy Sci. 99(9), 7191-7205.

Averós, X., Brossard, L., Dourmad, J.Y., de Greef, K.H., Edge, H.L., Edwards, S.A., Meunier-Salaün, M.C., 2010. A meta-analysis of the combined effect of housing and environmental enrichment characteristics on the behaviour and performance of pigs. Appl. Anim. Behav. Sci. 127 (34), 73-85.

Azizi, O., Kaufmann, O., Hasselmann, L., 2009. Relationship between feeding behaviour and feed intake of dairy cows depending on their parity and milk yield. Livest. Sci. 122(2), 156-161.

Azzaro, G., Caccamo, M., Ferguson, J.D., Battiato, S., Farinella, G.M., Guarnera, G.C., Puglisi, G., Petriglieri, R., Licitra, G., 2011. Objective estimation of body condition score by modelling cow body shape from digital images. J. Dairy Sci. 94(4), 2126-2137.

Bach, A., Iglesias, C., Busto, I., 2004. Technical note: A computerized system for monitoring feeding behavior and individual feed intake of dairy cattle. J. Dairy Sci. 87(12), 4207-4209.

Barkema, H.W., von Keyserlingk, M.A.G., Kastelic, J.P., Lam, T.J.G.M., Luby, C., Roy, J. P., LeBlanc, S.J., Keefe, G.P., Kelton, D.F., 2015. Invited review: Changes in the dairy industry affecting dairy cattle health and welfare. J. Dairy Sci. 98(11), 7426-7445.

Bercovich, A., Edan, Y., Alchanatis, V., Moallem, U., Parmet, Y., Honig, H., Maltz, E., Antler, A., Halachmi, I., 2013. Development of an automatic cow body condition scoring using body shape signature and Fourier descriptors. J. Dairy Sci. 96(12), 8047-8059.

Bewley, J.M., Boyce, R. E., Hockin, J., Munksgaard, L., Eicher, S.D., Einstein, M.E., Schutz, M.M., 2010. Influence of milk yield, stage of lactation, and body condition on dairy cattle lying behaviour measured using an automated activity monitoring sensor. J. Dairy Res. 77(01), 1-6.

Bewley, J.M., Peacock, A.M., Lewis, O., Boyce, R.E., Roberts, D.J., Coffey, M.P., Kenyon, S. J., Schutz, M.M., 2008. Potential for estimation of body condition scores in dairy cattle from digital images. J. Dairy Sci. 91(9), 3439-3453.

Botreau, R., Veissier, I., Butterworth, A., Bracke, M.B.M., Keeling, L.J., 2007. Definition of criteria for overall assessment of animal welfare. Anim. Welf. 16(2), 225-228.

Bracke, M.B.M., Spoolder, H.A.M., 2011. Review of wallowing in pigs: implications for animal welfare. Anim. Welf. 20(3), 347-363.

Brandl, N., Jørgensen, E., 1996. Determination of live weight of pigs from dimensions measured using image analysis. Comput. Electron. Agric. 15(1), 57-72.

Brendle, J., Hoy, S., 2011. Investigation of distances covered by fattening pigs measured with VideoMotionTracker®. Appl. Anim. Behav. Sci. 132(1), 27-32.

Broom, D.M., 2006. Behaviour and welfare in relation to pathology. Appl. Anim. Behav. Sci. 97(1), 73-83.

Brown-Brandl, T.M. Eigenberg, R.A. Purswell, J.L., 2013. Using thermal imaging as a method of investigating thermal thresholds in finishing pigs. Biosyst. Eng. 114(3), 327-333. 
Brown-Brandl, T.M., Rohrer, G.A., Eigenberg, R.A., 2013. Analysis of feeding behavior of group housed growing-finishing pigs. Comput. Electron. Agric. 96, 246-252.

Bruinsma, J., 2003. World agriculture: towards 2015/2030: an FAO perspective. Earthscan, London.

Bull, C.R., McFarlane, N.J.B., Zwiggelaar, R., Allen, C.J., Mottram, T.T., 1996. Inspection of teats by colour image analysis for automatic milking systems. Comput. Electron. Agric. 15(1), 15-26.

Caja, G., Castro-Costa, A., Knight, C.H., 2016. Engineering to support wellbeing of dairy animals. J. Dairy Res. 83(2), 136-147.

Cangar, Ö., Leroy, T., Guarino, M., Vranken, E., Fallon, R., Lenehan, J., Mee, J., Berckmans, D., 2008. Automatic real-time monitoring of locomotion and posture behaviour of pregnant cows prior to calving using online image analysis. Comput. Electron. Agric. 64(1), 53-60.

Chapinal, N., Veira, D. M., Weary, D. M., Von Keyserlingk, M.A.G., 2007. Technical note: Validation of a system for monitoring individual feeding and drinking behavior and intake in grouphoused cattle. J. Dairy Sci. 90(12), 5732-5736.

Colak, A., Polat, B., Okumus, Z., Kaya, M., Yanmaz, L.E., Hayirli, A., 2008. Short communication: early detection of mastitis using infrared thermography in dairy cows. J. Dairy Sci. 91(11), 4244-4248.

Conte, S., Bergeron, R., Gonyou, H., Brown, J., Rioja-Lang, F. C., Connor, L., Devillers, N., 2014. Measure and characterization of lameness in gestating sows using force plate, kinematic, and accelerometer methods. J. Anim. Sci. 92(12), 5693-5703.

Cook, N.J., Chabot, B., Lui, T., Bench, C.J., Schaefer, A.L., 2015. Infrared thermography detects febrile and behavioural responses to vaccination of weaned piglets. Anim. 9(02), 339-346.

Cortivo, P.D., Dias, E., Barcellos, J.O.J., Peripolli, V., Costa Jr, J.B.G., Dallago, B.S.L., McManus, C.M., 2016. Use of thermographic images to detect external parasite load in cattle. Comput. Electron. Agric. 127, 413-417.

Costa, A., Ismayilova, G., Borgonovo, F., Viazzi, S., Berckmans, D., Guarino, M., 2014. Image-processing technique to measure pig activity in response to climatic variation in a pig barn. Anim. Prod. Sci. 54(8), 1075-1083.

Doeschl-Wilson, A.B., Whittemore, C.T., Knap, P.W., Schofield, C.P., 2004. Using visual image analysis to describe pig growth in terms of size and shape. Anim. Sci. 79(3), 415-427.

Eddy, A.L., Van Hoogmoed, L.M., Snyder, J.R., 2001. The role of thermography in the management of equine lameness. Vet. J. 162(3), 172-181.

Ekkel, E.D., Spoolder, H.A., Hulsegge, I., Hopster, H., 2003. Lying characteristics as determinants for space requirements in pigs. Appl. Anim. Behav. Sci. 80(1), 19-30.

Fischer, A., Luginbühl, T., Delattre, L., Delouard, J.M., Faverdin, P., 2015. Rear shape in 3 dimensions summarized by principal component analysis is a good predictor of body condition score in Holstein dairy cows. J. Dairy Sci. 98(7), 4465-4476. 
Frost, A.R., Tillett, R.D., Welch, S.K., 2000. The development and evaluation of image analysis procedures for guiding a livestock monitoring sensor placement robot. Comput. Electron. Agric. 28(3), 229-242.

Gauthreaux, S.A., Livingston, J.W., 2006. Monitoring bird migration with a fixed- beam radar and a thermal- imaging camera. J. Fiel. Ornithol. 77(3), 319-328.

Gertheiss, J., Maier, V., Hessel, E.F., Staicu, A.M., 2015. Marginal functional regression models for analyzing the feeding behavior of pigs. J. Agric. Biol. Environ. Stat. 20(3), 353-370.

Gloster, J., Ebert, K., Gubbins, S., Bashiruddin, J., Paton, D.J., 2011. Normal variation in thermal radiated temperature in cattle: implications for foot-and-mouth disease detection. BMC, Vet. Res. 7(1), 1.

González-Velasco, H.M., García-Orellana, C.J., Macías-Macías, M., Gallardo-Caballero, R., García-Manso, A., 2011. A morphological assessment system for 'show quality' bovine livestock based on image analysis. Comput. Electron. Agric. 78(1), 80-87.

Grégoire, J., Bergeron, R., D'Allaire, S., Meunier-Salaün, M.C., Devillers, N., 2013. Assessment of lameness in sows using gait, footprints, postural behaviour and foot lesion analysis. Anim. 7(07), 1163-1173.

Gronskyte, R., Clemmensen, L.H., Hviid, M.S., Kulahci, M., 2016. Monitoring pig movement at the slaughterhouse using optical flow and modified angular histograms. Biosyst. Eng. 141, 19-30.

Gronskyte, R., Clemmensen, L.H., Hviid, M.S., Kulahci, M., 2015. Pig herd monitoring and undesirable tripping and stepping prevention. Comput. Electron. Agric. 119, 51-60.

Guo, Y.Z., Zhu, W.X., Jiao, P.P., Ma, C.H., Yang, J.J., 2015. Multi-object extraction from topview group-housed pig images based on adaptive partitioning and multilevel thresholding segmentation. Biosyst. Eng. 135, 54-60.

Guzhva, O., Ardö, H., Herlin, A., Nilsson, M., Åström, K., Bergsten, C., 2016. Feasibility study for the implementation of an automatic system for the detection of social interactions in the waiting area of automatic milking stations by using a video surveillance system. Comput. Electron. Agric. 127, 506-509.

Halachmi, I., Klopčič, M., Polak, P., Roberts, D.J., Bewley, J.M., 2013. Automatic assessment of dairy cattle body condition score using thermal imaging. Comput. Electron. Agric. 99, $35-40$.

Halachmi, I., Polak, P., Roberts, D.J., Klopcic, M., 2008. Cow body shape and automation of condition scoring. J. Dairy Sci. 91(11), 4444-4451.

Haley, D.B., Rushen, J., Passillé, A.D., 2000. Behavioural indicators of cow comfort: activity and resting behaviour of dairy cows in two types of housing. Can. J. Anim. Sci. 80(2), 257-263.

Han, J., Shao, L., Xu, D., Shotton, J., 2013. Enhanced computer vision with microsoft kinect sensor: A review. EEE Trans. Cybern. 43(5), 1318-1334.

Hillmann, E., Mayer, C., Schrader, L., 2004. Lying behaviour and adrenocortical response as indicators of the thermal tolerance of pigs of different weights. Anim. Welf. 13(3), 329-335. 
Hoffmann, G., Schmidt, M., Ammon, C., Rose-Meierhöfer, S., Burfeind, O., Heuwieser, W., Berg, W., 2013. Monitoring the body temperature of cows and calves using video recordings from an infrared thermography camera. Vet. Res. Comm. 37(2), 91-99.

Hovinen, M., Siivonen, J., Taponen, S., Hänninen, L., Pastell, M., Aisla, A. M., Pyörälä, S., 2008. Detection of clinical mastitis with the help of a thermal camera. J. Dairy Sci. 91(12), 45924598 .

Hristov, N.I., Betke, M., Kunz, T.H., 2008. Applications of thermal infrared imaging for research in aeroecology. Integr. Comp. Biol. 48(1), 50-59.

$\mathrm{Hu}$, J., Xin, H., 2000. Image-processing algorithms for behavior analysis of group-housed pigs. Behav. Res. Meth. Instrum. Comput. 32(1), 72-85.

Huhtala, A., Suhonen, K., Mäkelä, P., Hakojärvi, M., \& Ahokas J. (2007). Evaluation of instrumentation for cow positioning and tracking indoors. Biosyst. Eng., 96(3), 399-405.

Huynh, T.T.T., Aarnink, A.J.A., Gerrits, W.J.J., Heetkamp, M.J.H., Canh, T.T., Spoolder, H. A.M., Kemp, B., Verstegen, M.W.A., 2005. Thermal behaviour of growing pigs in response to high temperature and humidity. Appl. Anim. Behav. Sci. 91(1), 1-16.

James, C.A., Richardson, A.J., Watt, P.W., Maxwell, N.S., 2014. Reliability and validity of skin temperature measurement by telemetry thermistors and a thermal camera during exercise in the heat. J. Therm. Biol. 45, 141-149.

Jónsson, R., Blanke, M., Poulsen, N.K., Caponetti, F., Højsgaard, S., 2011. Oestrus detection in dairy cows from activity and lying data using on-line individual models. Comput. Electron. Agric. $76(1), 6-15$.

Jover, J.N., Alcaniz-Raya, M., Gomez, V., Balasch, S., Moreno, J.R., Colomer, V.G., Torres, A., 2009. An automatic colour-based computer vision algorithm for tracking the position of piglets. Span. J. Agric. Res. 7(3), 535-549.

Kashiha, M.A., Bahr, C., Ott, S., Moons, C. P., Niewold, T. A., Tuyttens, F., \& Berckmans D. (2014a). Automatic monitoring of pig locomotion using image analysis. Livest. Sci., 159, 141-148.

Kashiha, M., Bahr, C., Haredasht, S.A., Ott, S., Moons, C.P., Niewold, T.A., Ödberg, F.O., Berckmans, D, 2013a. The automatic monitoring of pigs water use by cameras. Comput. Electron. Agric. 90, 164-169.

Kashiha, M., Bahr, C., Ott, S., Moons, C.P., Niewold, T. A., Ödberg, F.O., Berckmans, D., 2013b. Automatic identification of marked pigs in a pen using image pattern recognition. Comput. Electron. Agric. 93, 111-120.

Kashiha, M., Bahr, C., Ott, S., Moons, C.P., Niewold, T.A., Ödberg, F.O., Berckmans, D., 2014b. Automatic weight estimation of individual pigs using image analysis. Comput. Electron. Agric. 107, 38-44.

Kastberger, G., Stachl, R., 2003. Infrared imaging technology and biological applications. Behav. Res. Meth. Instrum. Comput. 35(3), 429-439. 
Kolb, A., Barth, E., Koch, R., Larsen, R., 2010. Time- of- Flight Cameras in Computer Graphics. Comput. Graphics. Forum. 29(1), 141-159.

Kongsro, J., 2013. Development of a computer vision system to monitor pig locomotion. Open. J. Anim. Sci. 3, 254-260.

Kongsro, J., 2014. Estimation of pig weight using a Microsoft Kinect prototype imaging system. Comput. Electron. Agric., 109, 32-35.

Kuzuhara, Y., Kawamura, K., Yoshitoshi, R., Tamaki, T., Sugai, S., Ikegami, M., Kurokawa, Y., Obitsu, T., Okita, M., Sugino, T., Yasuda, T., 2015. A preliminarily study for predicting body weight and milk properties in lactating Holstein cows using a three-dimensional camera system. Comput. Electron. Agric. 111, 186-193.

Lao, F., Brown-Brandl, T., Stinn, J.P., Liu, K., Teng, G., Xin, H., 2016. Automatic recognition of lactating sow behaviors through depth image processing. Comput. Electron. Agric. 125, $56-62$.

Lee, J., Jin, L., Park, D., Chung, Y., 2016. Automatic recognition of aggressive behavior in pigs using a Kinect depth sensor. Sensors. 16(5), 631.

Lind, N.M., Vinther, M., Hemmingsen, R.P., Hansen, A.K., 2005. Validation of a digital video tracking system for recording pig locomotor behaviour. J. Neurosci. Methods. 143(2), 123-132.

Liu, B., Zhu, W., 2013. Segmentation improvement of pig contour based on registration and fusion of IR thermal and optical images. In 2013 Ninth International Conference on Natural Computation (ICNC), 1424-1428.

Marinello, F., Pezzuolo, A., Gasparini, F., Arvidsson, J., Sartori, L., 2015. Application of the Kinect sensor for dynamic soil surface characterization. Precis. Agric. 16(6), 601-612.

Maselyne, J., Adriaens, I., Huybrechts, T., De Ketelaere, B., Millet, S., Vangeyte, J., Van Nuffel, A., Saeys, W., 2015. Measuring the drinking behaviour of individual pigs housed in group using radio frequency identification (RFID). Anim. 1-10.

Maselyne, J., Van Nuffel, A., De Ketelaere, B., Vangeyte, J., Hessel, E.F., Sonck, B., Saeys, W., 2014. Range measurements of a High Frequency Radio Frequency Identification (HF RFID) system for registering feeding patterns of growing-finishing pigs. Comput. Electron. Agric. 108, 209220.

Matzner, S., Cullinan, V. I., Duberstein, C.A., 2015. Two-dimensional thermal video analysis of offshore bird and bat flight. Ecol. Inf. 30, 20-28.

Mccafferty, D.J., 2007. The value of infrared thermography for research on mammals: previous applications and future directions. Mamm. Rev. 37(3), 207-223.

McCafferty, D.J., Gilbert, C., Paterson, W., Pomeroy, P.P., Thompson, D., Currie, J.I., Ancel, A., 2011. Estimating metabolic heat loss in birds and mammals by combining infrared thermography with biophysical modelling. Comp. Biochem. Physiol. A: Mol. Integr. Physiol. 158(3), 337-345.

McFarlane, N.J., Schofield, C.P., 1995. Segmentation and tracking of piglets in images. Mach. Vision. Appl. 8(3), 187-193. 

Drinking behavior in nursery pigs: Determining the accuracy between an automatic water meter versus human observers. J. Anim. Sci. 87(12), 4173-4180.

Mendoza, F., Dejmek, P., Aguilera, J.M., 2006. Calibrated color measurements of agricultural foods using image analysis. Postharvest Biol. Technol. 41(3), 285-295.

Montanholi, Y.R., Odongo, N.E., Swanson, K.C., Schenkel, F.S., McBride, B.W., Miller, S.P., 2008. Application of infrared thermography as an indicator of heat and methane production and its use in the study of skin temperature in response to physiological events in dairy cattle (Bos taurus). J. Therm. Biol. 33(8), 468-475.

Murphy, E., Nordquist, R.E., van der Staay, F.J., 2014. A review of behavioural methods to study emotion and mood in pigs, Sus scrofa. Appl. Anim. Behav. Sci. 159, 9-28.

Nalon, E., Conte, S., Maes, D., Tuyttens, F.A.M., Devillers, N., 2013. Assessment of lameness and claw lesions in sows. Livest. Sci. 156(1), 10-23.

Nasirahmadi, A., Edwards, S. A., Sturm, B., 2016a. Investigating the effect of rooting substrate provision on the group lying behaviour of pigs using machine vision. CIGR, Aarhus.

Nasirahmadi, A., Hensel, O., Edwards, S. A. Sturm, B., 2017. A new approach for categorizing pig lying behaviour based on a Delaunay triangulation method. Anim. 11(1), 131-139.

Nasirahmadi, A., Hensel, O., Edwards, S.A., Sturm, B., 2016b. Automatic detection of mounting behaviours among pigs using image analysis. Comput. Electron. Agric. 124, 295-302.

Nasirahmadi, A., Richter, U., Hensel, O., Edwards, S., Sturm, B., 2015. Using machine vision for investigation of changes in pig group lying patterns. Comput. Electron. Agric. 119, 184190.

Nathan, D., Huynh, D.Q., Rubenson, J., Rosenberg, M., 2015. Estimating physical activity energy expenditure with the kinect sensor in an exergaming environment. PloS One, 10(5).

Nielsen, L.R., Pedersen, A.R., Herskin, M.S., Munksgaard, L., 2010. Quantifying walking and standing behaviour of dairy cows using a moving average based on output from an accelerometer. Appl. Anim. Behav. Sci. 127(1), 12-19.

Nilsson, M., Herlin, A.H., Ardö, H., Guzhva, O., Åström, K., Bergsten, C., 2015. Development of automatic surveillance of animal behaviour and welfare using image analysis and machine learned segmentation technique. Anim. 9(11), 1859-1865.

Oczak, M., Maschat, K., Berckmans, D., Vranken, E., Baumgartner, J., 2016. Automatic estimation of number of piglets in a pen during farrowing, using image analysis. Biosyst. Eng. 151, 81-89.

Oczak, M., Viazzi, S., Ismayilova, G., Sonoda, L.T., Roulston, N., Fels, M., Bahr, C., Hartung, J., Guarino, M., Berckmans, D., Vranken, E., 2014. Classification of aggressive behaviour in pigs by activity index and multilayer feed forward neural network. Biosyst. Eng. 119, 89-97. 

Annaiyan, A., Voos, H., Campoy, P., 2015. Towards an autonomous vision-based unmanned aerial system against wildlife poachers. Sensors, 15(12), 31362-31391.

Ott, S., Moons, C.P.H., Kashiha, M.A., Bahr, C., Tuyttens, F.A.M., Berckmans, D., Niewold, T.A., 2014. Automated video analysis of pig activity at pen level highly correlates to human observations of behavioural activities. Livest. Sci., 160, 132-137.

Ozkaya, S., 2013. The prediction of live weight from body measurements on female Holstein calves by digital image analysis. J. Agric. Sci. 151(04), 570-576.

Ozkaya, S., 2015. Prediction possibility of milk yield from udder measurements using digital image analysis on holstein cows. Ind. J. Anim. Res. 49(3), 388-391.

Pluk, A., Bahr, C., Poursaberi, A., Maertens, W., Van Nuffel, A., Berckmans, D., 2012. Automatic measurement of touch and release angles of the fetlock joint for lameness detection in dairy cattle using vision techniques. J. Dairy Sci. 95(4), 1738-1748.

Porto, S.M., Arcidiacono, C., Anguzza, U., Cascone, G., 2015. The automatic detection of dairy cow feeding and standing behaviours in free-stall barns by a computer vision-based system. Biosyst. Eng. 133, 46-55.

Porto, S.M., Arcidiacono, C., Anguzza, U., Cascone, G., 2013. A computer vision-based system for the automatic detection of lying behaviour of dairy cows in free-stall barns. Biosyst. Eng. 115(2), 184-194.

Porto, S.M., Arcidiacono, C., Guarnera, G.C., Cascone, G., 2012. Preliminary study for the implementation ofan image analysis algorithm to detect dairy cow presence at the feed barrier. J. Agric. Eng. Res. 42(4), 17-24.

Poursaberi, A., Bahr, C., Pluk, A., Van Nuffel, A., Berckmans, D., 2010. Real-time automatic lameness detection based on back posture extraction in dairy cattle: Shape analysis of cow with image processing techniques. Comput. Electron. Agric. 74(1), 110-119.

Pycinski, B., Czajkowska, J., Badura, P., Juszczyk, J., Pietka, E., 2016. Time-Of-Flight Camera, Optical Tracker and Computed Tomography in Pairwise Data Registration. PloS One. 11(7).

Quimby, W.F., Sowell, B.F., Bowman, J.G.P., Branine, M.E., Hubbert, M.E., Sherwood, H.W., 2001. Application of feeding behaviour to predict morbidity of newly received calves in a commercial feedlot. Can. J. Anim. Sci. 81(3), 315-320.

Rainwater-Lovett, K., Pacheco, J.M., Packer, C., Rodriguez, L.L., 2009. Detection of footand-mouth disease virus infected cattle using infrared thermography. Vet. J. 180(3), 317-324.

Reiners, K., Hegger, A., Hessel, E.F., Böck, S., Wendl, G., Van den Weghe, H.F., 2009. Application of RFID technology using passive HF transponders for the individual identification of weaned piglets at the feed trough. Comput. Electron. Agric. 68(2), 178-184.

Ringgenberg, N., Bergeron, R., Devillers, N., 2010. Validation of accelerometers to automatically record sow postures and stepping behaviour. Appl. Anim. Behav. Sci. 128(1), 37-44. 
Robert, B., White, B. J., Renter, D.G., Larson, R.L., 2009. Evaluation of three-dimensional accelerometers to monitor and classify behavior patterns in cattle. Comput. Electron. Agric. 67(1), 8084.

Rushen, J., Chapinal, N., De Passille, A.M., 2012. Automated monitoring of behaviouralbased animal welfare indicators. Anim. Welf. 21(3), 339.

Rutten, C.J., Velthuis, A.G.J., Steeneveld, W., Hogeveen, H., 2013. Invited review: Sensors to support health management on dairy farms. J. Dairy Sci. 96(4), 1928-1952.

Rydhmer, L., Zamaratskaia, G., Andersson, H.K., Algers, B., Guillemet, R., Lundström, K., 2006. Aggressive and sexual behaviour of growing and finishing pigs reared in groups, without castration. Acta. Agric. Scand. Sect. 56(2), 109-119.

Salau, J., Haas, J.H., Junge, W., Bauer, U., Harms, J., Bieletzki, S., 2014. Feasibility of automated body trait determination using the SR4K time-of-flight camera in cow barns. SpringerPlus. $3(1), 1$.

Schaefer, A.L., Cook, N., Tessaro, S.V., Deregt, D., Desroches, G., Dubeski, P.L., Tong, A. K.W., Godson, D.L., 2004. Early detection and prediction of infection using infrared thermography. Can. J. Anim. Sci. 84(1), 73-80.

Schlageter-Tello, A., Bokkers, E.A., Koerkamp, P.W.G., Van Hertem, T., Viazzi, S., Romanini, C.E., Halachmi, I., Bahr, C., Berckmans, D., Lokhorst, K., 2014. Manual and automatic locomotion scoring systems in dairy cows: A review. Preventive. Vet. Med. 116(1), 12-25.

Schofield, C.P., 1990. Evaluation of image analysis as a means of estimating the weight of pigs. J. Agric. Eng. Res. 47, 287-296.

Schofield, C.P., Marchant, J.A., White, R.P., Brandl, N., Wilson, M., 1999. Monitoring pig growth using a prototype imaging system. J. Agric. Eng. Res. 72(3), 205-210.

Shane, D.D., White, B. J., Larson, R.L., Amrine, D.E., Kramer, J.L., 2016. Probabilities of cattle participating in eating and drinking behavior when located at feeding and watering locations by a real time location system. Comput. Electron. Agric. 127, 460-466.

Shao, B., Xin, H., 2008. A real-time computer vision assessment and control of thermal comfort for group-housed pigs. Comput. Electron. Agric. 62(1), 15-21.

Shao, J., Xin, H., Harmon, J.D., 1998. Comparison of image feature extraction for classification of swine thermal comfort behavior. Comput. Electron. Agric. 19(3), 223-232.

Shelley, A.N., 2013. Monitoring Dairy Cow Feed Intake Using Machine Vision.

Shelley, Anthony N., 2013. Monitoring Dairy Cow Feed Intake Using Machine Vision . Theses and Dissertations, Electrical and Computer Engineering, University of Kentucky.

Shi, C., Teng, G., Li, Z., 2016. An approach of pig weight estimation using binocular stereo system based on LabVIEW. Comput. Electron. Agric. 129, 37-43. 
Song, X., Leroy, T., Vranken, E., Maertens, W., Sonck, B., Berckmans, D., 2008. Automatic detection of lameness in dairy cattle-Vision-based trackway analysis in cow's locomotion. Comput. Electron. Agric. 64(1), 39-44.

Sowell, B.F., Bowman, J.G.P., Branine, M.E., Hubbert, M.E., 1998. Radio frequency technology to measure feeding behavior and health of feedlot steers. Appl. Anim. Behav. Sci. 59(4), 277-284.

Spoliansky, R., Edan, Y., Parmet, Y., Halachmi, I., 2016. Development of automatic body condition scoring using a low-cost 3-dimensional Kinect camera. J. Dairy Sci. 99(9), 7714-7725.

Spoolder, H.A., Aarnink, A.A., Vermeer, H.M., van Riel, J., Edwards, S.A., 2012. Effect of increasing temperature on space requirements of group housed finishing pigs. Appl. Anim. Behav. Sci. 138(3), 229-239.

Sprecher, D.J., Hostetler, D.E., Kaneene, J.B., 1997. A lameness scoring system that uses posture and gait to predict dairy cattle reproductive performance. Theriogenology. 47(6), 1179-1187.

Stajnko, D., Brus, M., Hočevar, M., 2008. Estimation of bull live weight through thermographically measured body dimensions. Comput. Electron. Agric. 61(2), 233-240.

Stavrakakis, S., Guy, J.H., Syranidis, I., Johnson, G. ., Edwards, S.A., 2015a. Pre-clinical and clinical walking kinematics in female breeding pigs with lameness: A nested case-control cohort study. Vet. J. 205(1), 38-43.

Stavrakakis, S., Li, W., Guy, J.H., Morgan, G., Ushaw, G., Johnson, G.R., Edwards, S.A., 2015b. Validity of the Microsoft Kinect sensor for assessment of normal walking patterns in pigs. Comput. Electron. Agric. 117, 1-7.

Tasdemir, S., Urkmez, A., Inal, S., 2011. A fuzzy rule-based system for predicting the live weight of Holstein cows whose body dimensions were determined by image analysis. Turk. J. Elect. Eng. Comput. Sci. 19(4), 689-703.

Tasdemir, S., Urkmez, A., Inal, S., 2011. Determination of body measurements on the Holstein cows using digital image analysis and estimation of live weight with regression analysis. Comput. Electron. Agric. 76(2), 189-197.

Tillett, R.D., Onyango, C.M., Marchant, J.A., 1997. Using model-based image processing to track animal movements. Comput. Electron. Agric. 17(2), 249-261.

Trénel, P., Jensen, M.B., Decker, E.L., Skjøth, F., 2009. Technical note: quantifying and characterizing behavior in dairy calves using the IceTag automatic recording device. J. Dairy Sci. 92(7), 3397-3401.

Tsai, D.M., Huang, C.Y., 2014. A motion and image analysis method for automatic detection of estrus and mating behavior in cattle. Comput. Electron. Agric. 104, 25-31.

Hertem, V.T., Alchanatis, V., Antler, A., Maltz, E., Halachmi, I., Schlageter-Tello, A., Lokhorst, C., Viazzi, S., Romanini, C.E.B., Pluk, A., Bahr, C., 2013. Comparison of segmentation algorithms for cow contour extraction from natural barn background in side view images. Comput. Electron. Agric. 91, 65-74. 

Sonck, B., Saeys, W., 2015. Lameness detection in dairy cows: Part 2. Use of sensors to automatically register changes in locomotion or behavior. Anim. 5(3), 861-885.

1071

1072

1073

1074

1075

1076

1077

1078

1079

1080

1081

1082

1083

1084

1085

1086

1087

1088

1089

1090

1091

1092

1093

1094

1095

1096

1097

1098

1099

1100

1101

1102

1103

1104

1105
Van Riet, M.M.J., Millet, S., Aluwé, M., Janssens, G.P.J., 2013. Impact of nutrition on lameness and claw health in sows. Livest. Sci. 156(1), 24-35.

Vázquez-Arellano, M., Griepentrog, H.W., Reiser, D., Paraforos, D.S., 2016. 3-D Imaging Systems for Agricultural Applications - A Review. Sensors. 16(5), 618.

Viazzi, S., Bahr, C., Schlageter-Tello, A., Van Hertem, T., Romanini, C.E.B., Pluk, A., Halachmi, I., Lokhorst, C., Berckmans, D., 2013. Analysis of individual classification of lameness using automatic measurement of back posture in dairy cattle. J. Dairy Sci. 96(1), 257-266.

Viazzi, S., Bahr, C., Van Hertem, T., Schlageter-Tello, A., Romanini, C.E.B., Halachmi, I., Lokhorst, C., Berckmans, D., 2014a. Comparison of a three-dimensional and two-dimensional camera system for automated measurement of back posture in dairy cows. Comput. Electron. Agric. 100,139147.

Viazzi, S., Ismayilova, G., Oczak, M., Sonoda, L.T., Fels, M., Guarino, M., Vranken, E., Hartung, J., Bahr, C., Berckmans, D., 2014b. Image feature extraction for classification of aggressive interactions among pigs. Comput. Electron. Agric. 104, 57-62.

Viola, P., Jones, M.J., 2004. Robust real-time face detection. Int. J. Comput. Vision. 57(2), $137-154$

Wang, Y., Yang, W., Winter, P., Walker, L., 2008. Walk-through weighing of pigs using machine vision and an artificial neural network. Biosyst. Eng. 100(1), 117-125.

Weber, A., Salau, J., Haas, J.H., Junge, W., Bauer, U., Harms, J., Suhr, O., Schönrock, K., Rothfuß, H., Bieletzki, S., Thaller, G., 2014. Estimation of backfat thickness using extracted traits from an automatic 3D optical system in lactating Holstein-Friesian cows. Livest. Sci. 165, 129-137.

Westlund, J.K., D’Mello, S.K., Olney, A.M., 2015. Motion Tracker: Camera-based monitoring of bodily movements using motion silhouettes. PloS One. 10(6).

Wirthgen, T., Zipser, S., Franze, U., Geidel, S., Lempe, G., 2011. Automatic infrared based temperature measuring system for health monitoring in veterinary applications. IEEE SENSORS Proceedings, Limerick, 1800-1803.

Wolfger, B., Manns, B.J., Barkema, H.W., Schwartzkopf-Genswein, K.S., Dorin, C., Orsel, K., 2015. Evaluating the cost implications of a radio frequency identification feeding system for early detection of bovine respiratory disease in feedlot cattle. Preventive Vet. Med. 118(4), 285-292.

Wongsriworaphon, A., Arnonkijpanich, B., Pathumnakul, S., 2015. An approach based on digital image analysis to estimate the live weights of pigs in farm environments. Comput. Electron. Agric. 115, 26-33.

Wu, J., Tillett, R., McFarlane, N., Ju, X., Siebert, J.P., Schofield, P., 2004. Extracting the three-dimensional shape of live pigs using stereo photogrammetry. Comput. Electron. Agric. 44(3), 203-222. 

Detection from Kinect Sensed Images for Livestock Monitoring and Assessment. IEEE International Conference on Computer and Information Technology; Ubiquitous Computing and Communications; Dependable, Autonomic and Secure Computing; Pervasive Intelligence and Computing, Liverpool, 1154-1157.

Zhu, W., Pu, X., Li, X., Zhu, X., 2009. Automated detection of sick pigs based on machine vision. Proceedings of IEEE International Conference on Intelligent Computing and Intelligent Systems, Shanghai, People's Republic of China, 790-794. 
Table 1- Validation criteria for machine vision techniques.

\begin{tabular}{lcc}
\hline Performance & Equation for calculation \\
criterion & \\
\hline Sensitivity (\%) & $\frac{T P}{T P+F N}$ & \\
& $\frac{T N}{T N+F P}$ & \\
Specificity (\%) & TN= true positive (correct detection of a relevant behaviour) \\
Accuracy (\%) & $\frac{T P+T N}{T P+F P+T N+F N}$ & \\
Error rate (\%) & $\frac{F P}{T P+F P}$ & $\mathrm{FP}=$ false positive (incorrect detection a relevant behaviour) \\
Precision (\%) & $\frac{T P}{T P+F P}$ & \\
& &
\end{tabular}

1133

1134

1135

1136

1137

1138

1139

1140

1141 
1143 Table 2- Summary of automatic 2D and 3D image processing methods used for cattle monitoring.

\begin{tabular}{|c|c|c|c|}
\hline Monitoring & Imaging system & Technique & Source \\
\hline \multirow{3}{*}{ Live weight } & 2D (CCD camera) & $\begin{array}{l}\text { Based on hip height, body length, hip width and chest } \\
\text { depth. }\end{array}$ & Tasdemir et al., 2011a; 2011b; Ozkaya, 2013 \\
\hline & 2D (Thermal camera) & Based on tail root and front hoof templates. & Stajnko et al., 2008 \\
\hline & 3D (TOF sensor) & Based on 3D and contour features of body. & Anglart, 2016 \\
\hline \multirow{6}{*}{ Body shape and } & 2D (CCD camera) & Based on anatomical points (points around hook and tail). & Bewley et al., 2008; Azzaro et al., 2011 \\
\hline & 2D (CCD camera) & $\begin{array}{l}\text { Based on the angles and distances between anatomical } \\
\text { points and the ED from each point in the normalized tail- }\end{array}$ & Bercovich et al., 2013 \\
\hline & & head contour to the shape centre. & \\
\hline & 2D (CCD camera) & Based on RGB and body features. & González-Velasco et al., 2011; Hertem et al., 2013 \\
\hline & 2D (Thermal camera) & Based on thickness of fat and muscle layers. & Halachmi et al., 2008; Halachmi et al., 2013 \\
\hline & & Based on body features and back postures. & \\
\hline
\end{tabular}


3D (TOF and depth imaging

sensors)
Weber et al., 2014; Salau et al., 2014; Fischer et al., 2015; Kuzuhara et

al., 2015; Spoliansky et al., 2016
2D (Thermal camera) Based on udder surface temperature.

Health and disease

2D (Thermal camera)

Based on body surface temperature.

Based on the Viola-Jones algorithm.

Based on change in volume of food.

Shelley, 2013

\begin{tabular}{|c|c|c|c|}
\hline & 2D (Thermal camera) & Based on the Viola-Jones algorithm. & Porto et al., 20 \\
\hline drinking behaviour & 3D (Structured light & Based on change in volume of food. & Shelley, 2013 \\
\hline
\end{tabular}

3D (Structured light

illumination scanning)
Schaefer et al., 2004; Montanholi et al., 2008; Hovinen et al., 2008;

Colak et al., 2008; Rainwater-Lovett et al., 2009; Wirthgen et al., 2011;

Gloster et al., 2011; Hoffmann et al., 2013

Based on the $x-y$ coordinates of the geometric centre of the

Cangar et al., 2008

Lying behaviour $\quad 2 \mathrm{D}(\mathrm{CCD}$ camera $)$

animal

Based on Viola and Jones algorithm.

Porto et al., 2013

Locomotion and

lameness behaviour

2D (CCD camera)

Based on body features extraction from binary image.

Song et al., 2008 
Based on the touch and release angles in the fetlock joint of leg along with pressure mat data.

Based on the curvature of the back of each animal.

Poursaberi et al., 2010; Viazzi et al., 2013

3D (Kinect sensor)

Based on 3D and 2D features of depth and binary images.

Based on tracking hooks and spine of animal in depth

image.
Viazzi et al., 2014a

Abdul Jabbar et al., 2017
3D (Depth video)

Aggressive

behaviour

2D (CCD camera)

Based on geometric features between animals.

Guzhva et al., 2016

(n)

Mounting behaviour

2D (CCD camera)

Based on motion detection and length of moving animals.

Tsai and Huang, 2014

1144 
1147 Table 3- Summary of Automatic 2D and 3D image processing methods used for pig monitoring.

\begin{tabular}{|c|c|c|c|}
\hline Monitoring & Imaging system & Technique & Source \\
\hline \multirow{5}{*}{ Live weight } & \multirow{3}{*}{ 2D (CCD camera) } & $\begin{array}{l}\text { Based on length and width dimension and boundary } \\
\text { area. }\end{array}$ & $\begin{array}{l}\text { Schofield, 1990; Brandl and Jorgensen, 1996; White et al., 1999; } \\
\text { Doeschl-Wilson et al., } 2004\end{array}$ \\
\hline & & & \\
\hline & & $\begin{array}{l}\text { Based on area, convex area, perimeter, eccentricity, } \\
\text { major and minor axis length. }\end{array}$ & $\begin{array}{l}\text { Wang et al., 2008; Kashiha et al., 2014b ; Wongsriworaphon et al., } \\
\text { 2015; }\end{array}$ \\
\hline & 3D (Kinect sensor) & Based on volume and area of body. & Kongsro, 2014; Zhu et al., 2015 \\
\hline & 3D (Stereo Vision) & Based on body length, withers height and back area. & Shi et al., 2016 \\
\hline \multirow{3}{*}{$\begin{array}{l}\text { Body shape and } \\
\text { condition }\end{array}$} & 2D (Thermal camera) & Based on shape and contour detection. & Liu and Zhu, 2013 \\
\hline & \multirow[t]{2}{*}{ 3D (Stereo photogrammetry) } & \multirow[t]{2}{*}{ Based on triangulating on animal natural skin texture. } & $\begin{array}{l}\text { Wu et al., } \\
2004\end{array}$ \\
\hline & & & Wu et al., 2004 \\
\hline \multirow[t]{2}{*}{ Health and disease } & 2D (CCD camera) & Based on daily movement pattern in binary images. & Zhu et al., 2009 \\
\hline & \multirow{3}{*}{ 2D (CCD camera) } & Based on blob edge and an ellipse fitting technique. & McFarlane and Schofield, 1995; Kashiha et al., 2013b \\
\hline \multirow[t]{2}{*}{ Tracking } & & Based on $x-y$ coordinates of shape. & Tillett et al., 1997 \\
\hline & & $\begin{array}{l}\text { Based on positions of locatable features (kinks) of } \\
\text { body. }\end{array}$ & Frost et al., 2000 \\
\hline
\end{tabular}


Based on RGB values.

Based on building up support maps and Gaussian

model.

Learning based segmentation

Based on adaptive partitioning and multilevel

thresholding segmentation.
Jover et al., 2009

Ahrendt et al., 2011

Nilsson et al., 2015

Guo et al., 2015

\begin{tabular}{|c|c|c|c|}
\hline \multirow{2}{*}{$\begin{array}{l}\text { Feeding and } \\
\text { drinking behaviour }\end{array}$} & 2D (CCD camera) & $\begin{array}{l}\text { Based on fitted ellipse features and distance to drinking } \\
\text { nipple. }\end{array}$ & Kashiha et al., 2013a \\
\hline & 3D (Kinect sensor) & $\begin{array}{l}\text { Based on depth image and } x-y \text { coordinates of binary } \\
\text { image. }\end{array}$ & Lao et al., 2016 \\
\hline \multirow{3}{*}{ Lying behaviour } & \multirow{3}{*}{ 2D (CCD camera) } & Based on features of binary image. & Shao et al., 1998; Shao and Xin, 2008 \\
\hline & & Based on the pixel intensity in binary image. & Costa et al., 2014 \\
\hline & & Based on fitted ellipse and the DT features. & Nasirahmadi et al., 2015; 2016a ; 2017 \\
\hline \multirow{2}{*}{$\begin{array}{l}\text { Locomotion and } \\
\text { lameness behaviour }\end{array}$} & \multirow{2}{*}{ 2D (CCD camera) } & Based on RGB and image map values. & Kongsro, 2013 \\
\hline & & Based on activity index. & Ott et al., 2014 \\
\hline
\end{tabular}


Based on fitted ellipse features in consecutive frames. Kashiha et al., 2014a; Nasirahmadi et al., 2015

Based on optical flow pattern.

3D (Kinect sensor)

Aggressiv

behaviour

$2 \mathrm{D}$ (CCD camera)

3D (Kinect sensor)
Gronskyte et al., 2015; Gronskyte et al., 2016

Stavrakakis et al., 2015a; 2015b
Based on Vicon 3D optoelectronic motion analysis.

Based on motion history image and activity index.

Based on features from depth image. 
Figure captions

1150

1151 Fig. 1- The principles of 3D depth sensing.

1152

Fig. 2- Delaunay triangulation for pig lying detection (left), ellipse features (right) (Nasirahmadi et al., 1153 2015)

1154 Fig. 3- Fitted ellipses in different pig lying patterns; touching ellipses with their parameters and

1155 Delaunay triangulation for lying detection in close, normal and far patterns (Nasirahmadi et al., 2017).

1156 Fig. 4- Combining pressure and image data for calculation of touch and release angles in cow 1157 locomotion analysis (Pluk et al., 2012).

1158 Fig. 5- Example of depth image representation with a 3D camera: a raw depth cow image (left), the 1159 same image with the background removed (right); the darkened regions indicate higher pixels (Abdul Jabbar et al., 2017).

1161 Fig. 6- Detection of a moving pig in image processing; ellipse fitted to pigs and angular and linear movements at frame $t$ and 5 seconds later $(t+5)$ (Nasirahmadi et al., 2015).

Fig. 7- Mounting event among pigs, (top) grey images during mounting event, (bottom) binary images and the ED between two pigs during a mounting event (Nasirahmadi et al., 2016b). 
1169 Fig.1

1170

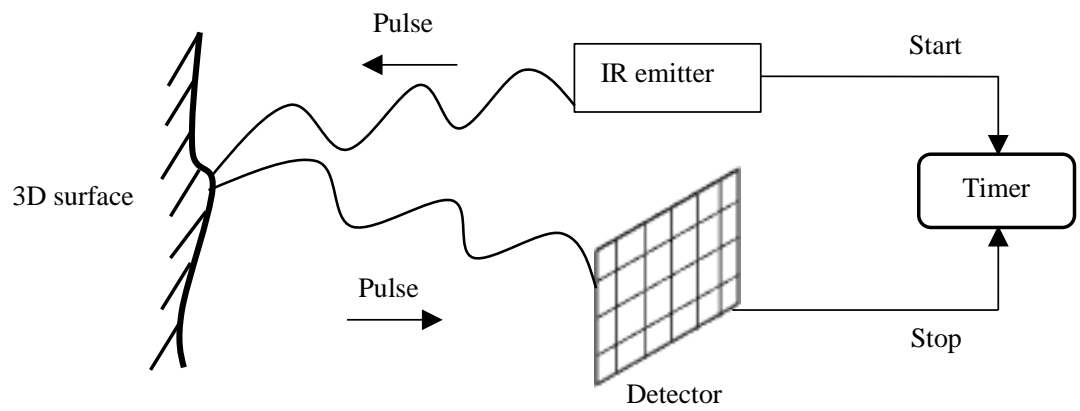


1172 Fig.2

1173
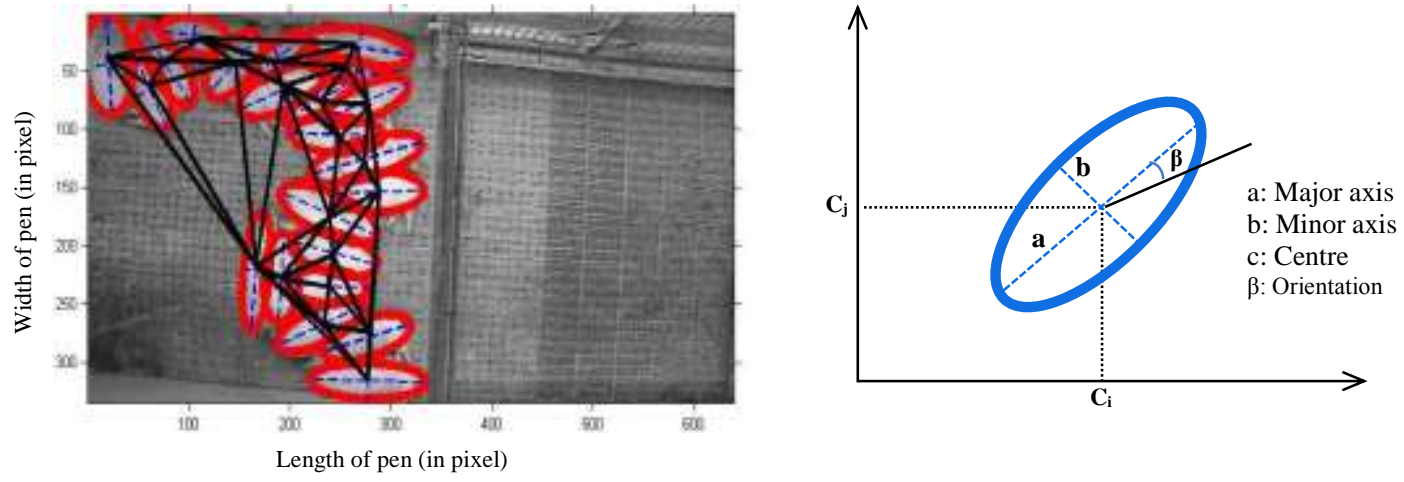
$1174 \quad$ Fig .3

1175
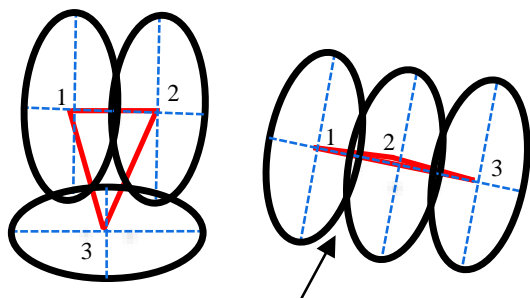

Huddle together

(close pattern)
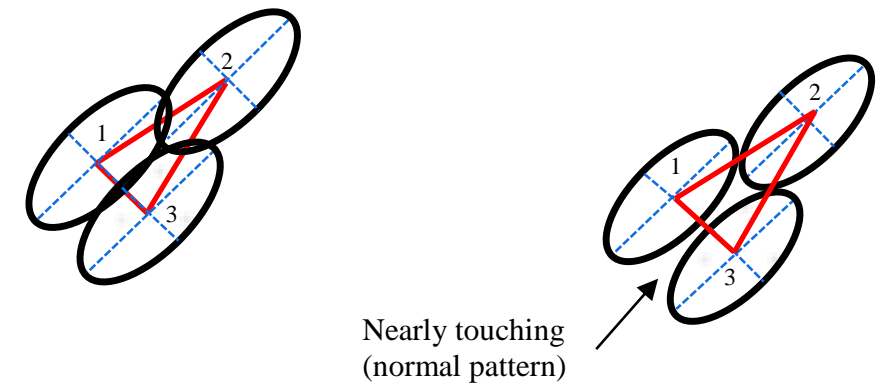

Avoid touching

(far pattern)
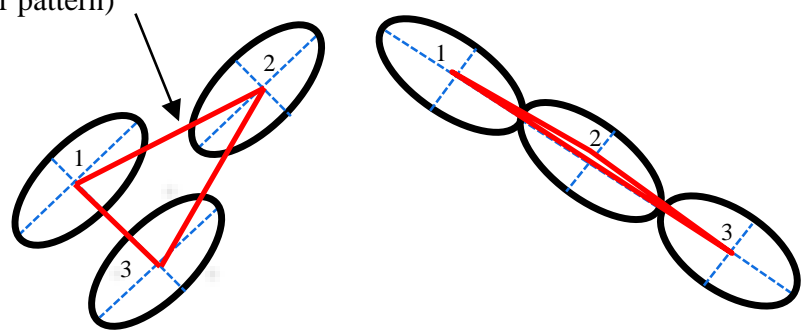
$1176 \quad$ Fig .4

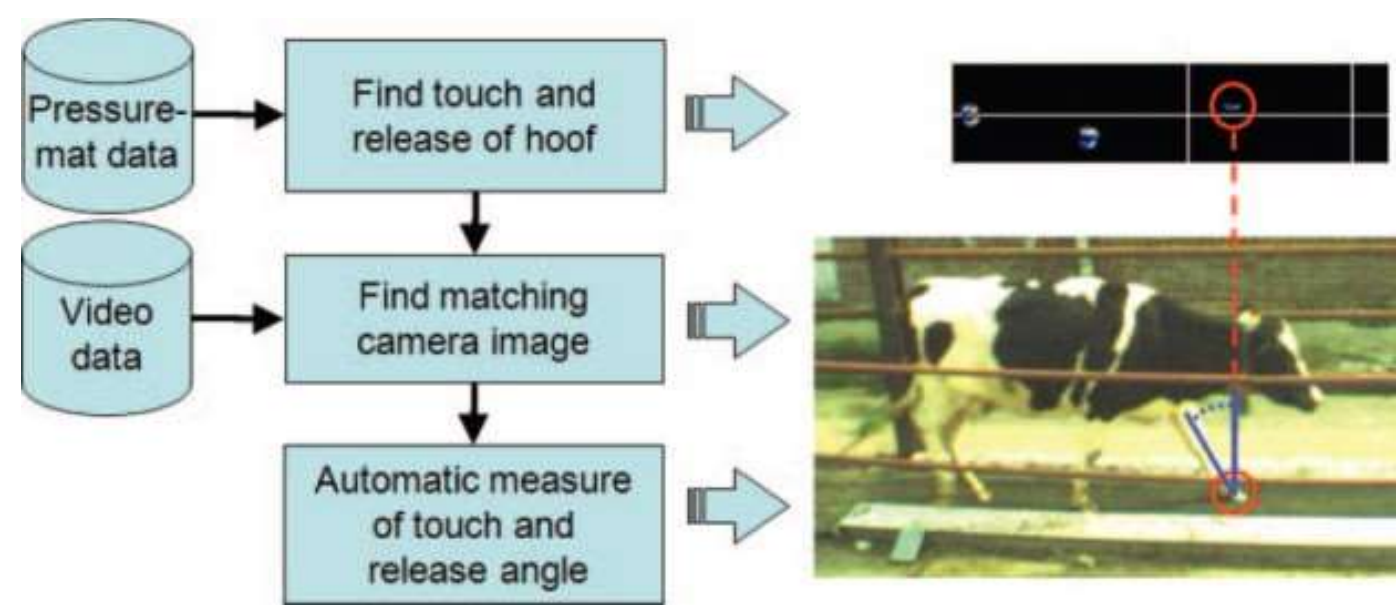


$1178 \quad$ Fig .5

1179
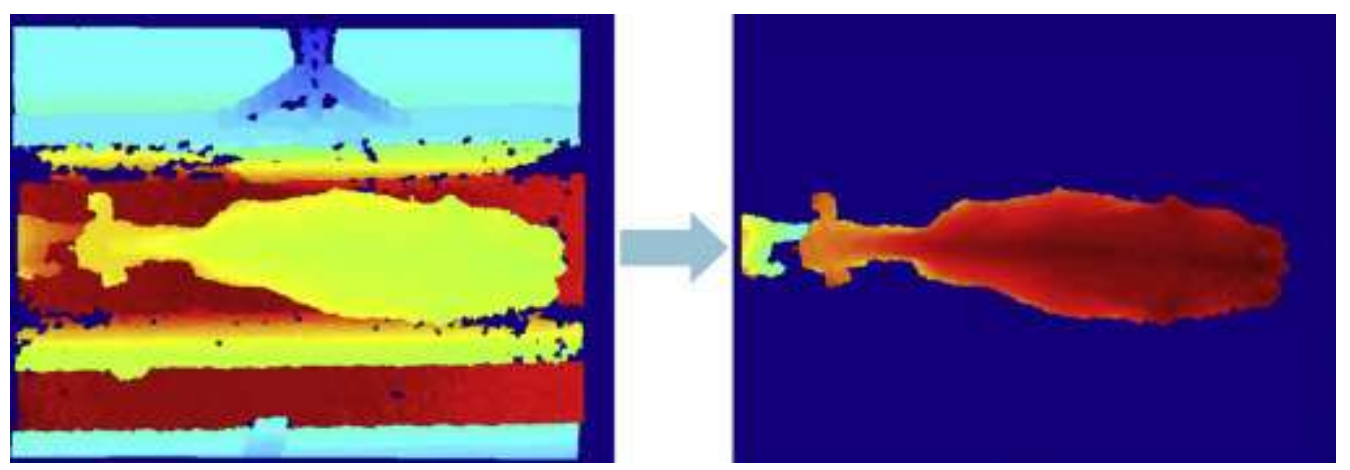
1181 Fig .6

1182

1183

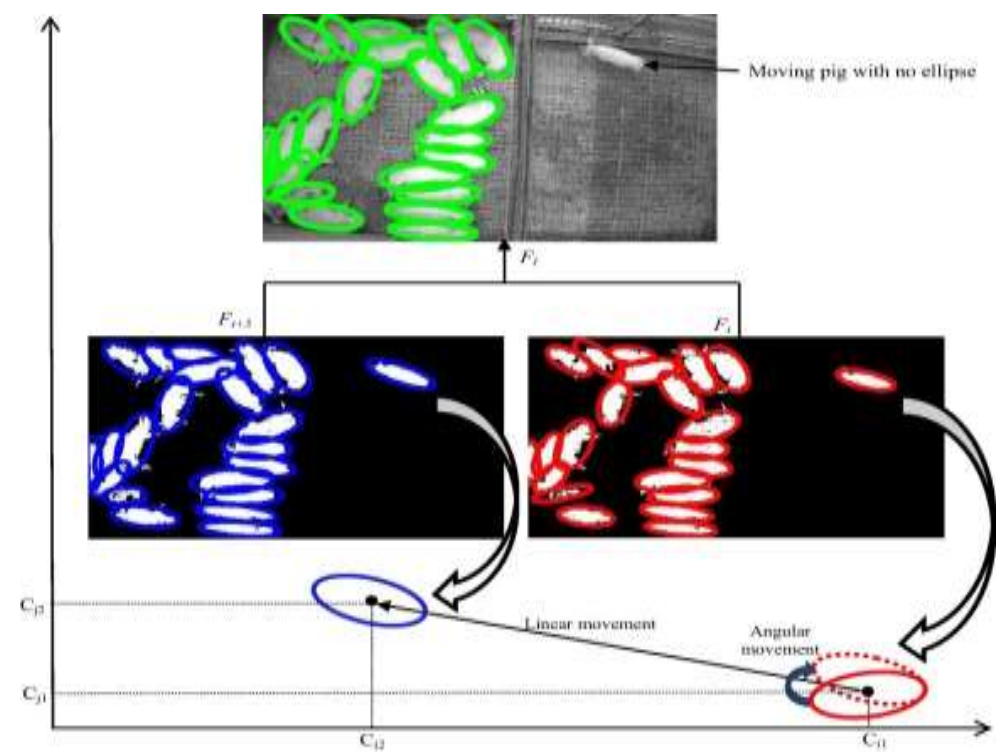

1184

1185

1186

1187

1188

1189

1190

1191

1192

1193

1194

1195

1196

1197

1198

1199 
$1200 \quad$ Fig.7

1201

1202
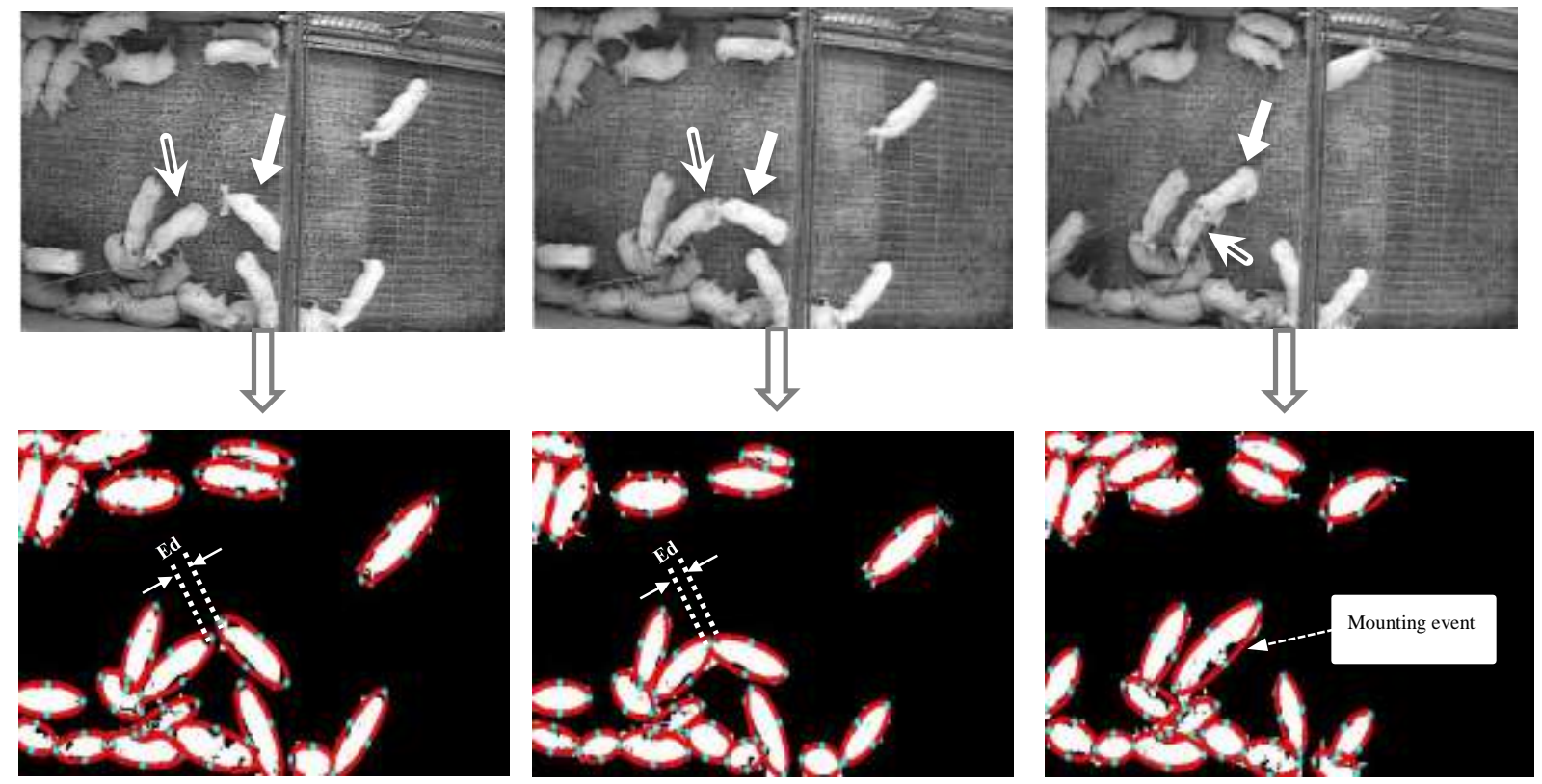

1203

1204 